\title{
An Experimental and Kinetic Modeling Study of Laminar Flame Speed of Dimethoxymethane and Ammonia Blends
}

\author{
Ayman M Elbaz ${ }^{1, *}$, Binod Raj Giri, ${ }^{1, *}$, Gani Issayev ${ }^{1}$, Krishan P. Shrestha ${ }^{2}$, Fabian Mauss ${ }^{2}$, Aamir \\ Farooq $^{1}$, and William L Roberts ${ }^{1}$ \\ ${ }^{1}$ King Abdullah University of Science and Technology (KAUST), Clean Combustion Research Center, \\ Physical Sciences and Engineering Division, Thuwal 23955-6900, Saudi Arabia \\ ${ }^{2}$ Thermodynamics and Thermal Process Engineering, Brandenburg University of Technology, Siemens- \\ Halske-Ring 8, 03046 Cottbus, Germany \\ *Corresponding authors’ E-mail: $\quad$ ayman.elhagrasy@kaust.edu.sa; binod.giri@kaust.edu.sa
}

\begin{abstract}
Ammonia $\left(\mathrm{NH}_{3}\right)$ is considered a promising carbon-neutral fuel, with high hydrogen content, that can diversify the global energy system. Blending ammonia with a highly reactive fuel is one possible strategy to enhance its combustion characteristics. Here, an investigation of blends of $\mathrm{NH}_{3}$ and dimethoxymethane (DMM), a biofuel with high fuel-born oxygen content and no carboncarbon bonds, is rep`orted. Unstretched laminar burning velocity $\left(S_{L}\right)$ and Markstein length of different $\mathrm{NH}_{3} / \mathrm{DMM}$ blends were experimentally determined using spherically propagating premixed flames. The DMM mole fraction was varied from 0.2 to 0.6 while measuring $S_{L}$ at 298 $\mathrm{K}, 0.1 \mathrm{MPa}$ and equivalence ratios $(\Phi)$ over a range of 0.8 to 1.3. The addition of DMM was found to immensely enhance the combustion characteristics of ammonia. DMM 20\% (by mole fraction) in $\mathrm{NH}_{3} / \mathrm{DMM}$ blend increased $S_{L}$ more than a factor of 3 over neat ammonia; such enhancement was found to be comparable with $60 \% \mathrm{CH}_{4}$ in $\mathrm{NH}_{3}(\Phi=0.9-1.1)$ blends. Increasing $\Phi$ was found to significantly decrease the burned gas Markestein length for lean cases, whereas a negligible effect was observed for rich mixtures. A composite chemical kinetic model of $\mathrm{DMM} / \mathrm{NH}_{3}$, aimed
\end{abstract}


at interpreting the high-temperature combustion chemistry, was able to reliably predict $S_{L}$ for neat $\mathrm{NH}_{3}$ and DMM flames. Also, the predictive capability of the kinetic model to describe $S_{L}$ for $\mathrm{DMM} / \mathrm{NH}_{3}$ blends is reasonably good. Sensitivity analysis and reaction paths analysis indicated that the $\mathrm{NH}_{3} / \mathrm{DMM}$ blends could be understood as the dual oxidation processes of the individual fuels which are competing for the same radical pool.

Keywords: Ammonia; Dimethoxymethane; Laminar flame speed; Markestein length; Kinetic model.

\section{Nomenclature}

$\begin{array}{llll}A & \text { flame area } & T_{b} & \text { burnt gas temperature } \\ \mathrm{CN} & \text { cetane number } & T_{i} & \text { mixture initial temperature } \\ C_{p} & \text { specific heat at constant pressure of } & T^{o} & \text { inner layer temperature } \\ & \text { the mixture } & T_{u} & \text { unburnt mixture temperature } \\ \mathrm{CVSV} & \text { Constant Volume Spherical Vessel } & \mathrm{Ze} & \text { Zeldovich number } \\ \mathrm{DME} & \text { Dimethyl ether } & \chi_{\mathrm{DMM}} & \text { DMM mole fraction in the fuel blend } \\ \mathrm{DMM} & \text { Dimethoxymethane } & \sigma & \text { the expansion coefficient: } \rho_{u} / \rho_{b} \\ K & \text { total stretch rate } & \Phi & \text { mixture equivalence ratio } \\ L_{b} & \text { burned gas Markstein length } & \lambda & \text { thermal conductivity of the mixture } \\ L e & \text { Lewis number } & t & \text { time from ignition } \\ \text { OMEs } & \text { Oxymethylene dimethyl ethers } & \rho_{b} & \text { burnt gas density } \\ P_{i} & \text { mixture initial pressure } & \rho_{u} & \text { unburnt mixture density } \\ R_{f} & \text { schlieren flame radius } & \xi_{E} & \text { normalized enhancement factor } \\ S_{L} & \text { unstretched laminar burning velocity } & \delta_{L} & \text { preheat flame thickness } \\ & \text { relative to the unburnt gas } & & \\ S_{n} & \text { stretched propagating flame speed } & & \\ S_{S} & \text { unstretched laminar burning velocity } & & \\ & \text { relative to the burnt gas } & & \end{array}$




\section{Introduction}

Greenhouse gas emission from the burning of fossil fuels has steadily risen since the industrial revolution. The adoption of carbon-free fuels will not only help diversify the global energy system but also reduce our dependence on fossil fuels. Hydrogen is a carbon-free fuel; however, the high cost of hydrogen transport and storage makes its sustainable utilization very challenging. On the contrary, due to the high percentage of hydrogen in ammonia ( $17.7 \%$ by weight), it can be regarded as a carbon-free hydrogen carrier with a lower cost of storage and transport $[1,2]$. Similar to hydrogen, ammonia can be produced from renewable resources [3]. Consequently, one possible step ahead towards carbon-free combustion can be the utilization of ammonia in combustion-based energy devices. However, there are some barriers of using ammonia as a fuel due to its low flammability limits, relatively low energy density (LHV $18.6 \mathrm{MJ} / \mathrm{kg}$ ), high ignition energy, and high NO emissions $[1,4]$.

There is a growing interest in investigating the combustion characteristics of ammonia blends. Blending ammonia with hydrocarbon fuels results in fuels of higher energy density and flame speeds, and lower $\mathrm{CO}_{2}$ emissions than the conventional hydrocarbon. Recently, Kobayashi et al. [5] provided an extensive review of the combustion behavior of different ammonia blends. There are a couple of fundamental studies on the combustion behavior of ammonia blended with hydrocarbons and hydrogen. For example, over a pressure range of 0.1-0.5 $\mathrm{MPa}$, the relatively low laminar burning velocity, $S_{L}$, of neat ammonia was found to exhibit similar trends as that of the hydrocarbon fuels showing maximum $S_{L}$ at $\Phi \approx 1.1$ [1]. In $\mathrm{CH}_{4} / \mathrm{NH}_{3}$ blend, the laminar burning velocity was seen to increase with the increase of $\mathrm{CH}_{4}$ concentration in the mixture $[2,6]$, and the same trend was reported for $\mathrm{C}_{3} \mathrm{H}_{8} / \mathrm{NH}_{3}$ flames [7] as well. Blending $\mathrm{NH}_{3}$ with hydrogen enhanced $S_{L}$ 
exponentially with the increase of hydrogen mole fraction in the blend [8]. Recently, Otomo et al. [9] proposed a chemical kinetic model to predict $S_{L}$ and ignition delay times of $\mathrm{H}_{2} / \mathrm{NH}_{3}$ blends.

In addition, the use of alternative fuels or new fuel formulations for future internal combustion engines is another pathway to alleviate the oil crisis and to achieve high efficiency and clean combustion. To this end, oxygenated fuels can be promising candidates $[10,11]$. Recently, synthetic oxymethylene dimethyl ethers (OMEs, $\left.\mathrm{CH}_{3} \mathrm{O}-\left(\mathrm{CH}_{2} \mathrm{O}\right)_{n}-\mathrm{CH}_{3}, \mathrm{n}=1-5\right)$ has attracted considerable interest [10]. Comparing with diesel fuel, OMEs exhibited higher engine efficiency with lower $\mathrm{HC}, \mathrm{CO}, \mathrm{NOx}$, soot emissions due to its higher fuel-born oxygen, higher ignitability, higher volatility, absence of carbon-carbon bonds [11]. OMEs was used as pilot fuels for natural gas dual-fuel combustion [12]. Methanol is the building block of OMEs production; the former chemical can be produced from coal, natural gas, or biomass through syngas [13]. Depending on the feedstock type, and subsequent gasification, syngas can also be obtained from renewable resources via different methodologies [14]. A cost assessment showed that OME production is competitive with conventional diesel on a tonnage base [15]. Therefore, OMEs has a substantial advantage over other alternative fuels in need of massive public subsidies.

Recently, studies in Internal Combustion Engines (ICE) have focused on using ammonia blended with oxygenated fuels, driven by the demand for alternative fuels $[16,17]$. In these studies, ammonia was blended with dimethyl ether, DME, $\left.\left(\mathrm{CH}_{3} \mathrm{O}-\left(\mathrm{CH}_{2} \mathrm{O}\right)_{\mathrm{n}}-\mathrm{CH}_{3}\right), \mathrm{n}=0\right)$ and tested in a compression-ignition engine, where DME served as a co-fuel to initiate the combustion. Their results showed that a higher fraction of ammonia in the blends caused longer ignition delays and limited the engine load. These observations highlight the need to characterize the combustion properties of $\mathrm{NH}_{3}$ blended with different co-fuels as combustion promoters. Although both methanol and DME are attractive oxygenated-fuels for future sustainability, methanol is toxic, and 
DME is gaseous. Therefore, DMM (dimethoxymethane, $\mathrm{CH}_{3} \mathrm{O}-\mathrm{CH}_{2} \mathrm{O}-\mathrm{CH}_{3}, \mathrm{OME} 1$ ) offers an excellent chemical feedstock for more convenient storage and handling. DMM, an oxygenated biofuel $\left(42 \%\right.$ wt $\left.\mathrm{O}_{2}\right)$ with a high $\mathrm{H} / \mathrm{C}$ ratio, has recently drawn considerable attention $[18,19]$. Pure DMM burns clean with no soot [20], and also, there are promising reports of DMM reducing soot/PAH substantially when blended with diesel fuels [21-23]. However, the physical properties of DMM include low boiling point, low cetane number $(\mathrm{CN})$, low viscosity, lubricity and high volatility lead to the need for the modifications of fuel supply/injection systems. Hence, the use of DMM as a blend with diesel or with additives. Omari et al. [24] indicated that an optimum blending ratio $(\mathrm{DMM} /$ diesel $\mathrm{wt} \%)$ of $35 \%$ is the best compromise between soot reduction and the deterioration of fuel properties such as heating value and $\mathrm{CN}$. At present, DMM production relies on the catalytic oxidation of methanol and methanol condensation with formaldehyde [25]. Several other routes utilizing methanol or $\mathrm{CO}_{2}$ and $\mathrm{H}_{2}$ to produce DMM in one step have been proposed $[26,27]$.

From the kinetic modeling perspective, numerous hydrocarbon mechanisms blended with the sub-mechanism of $\mathrm{NH}_{3}$ oxidation have been used to predict the combustion characteristics of $\mathrm{NH}_{3}$ dual fuel systems. Recently, Han et al. [28] used the available kinetic models to validate their measurements of the atmospheric laminar burning velocity of $\mathrm{NH}_{3}$ blended with $\mathrm{H}_{2}, \mathrm{CO}$, and $\mathrm{CH}_{4}$. They showed that none of the available kinetic models (GRI-Mech 3.0 [29], Okafor et al. [2], and SanDiego [30]) could accurately capture the experimental data which they attributed to the uncertainty in the rate parameters of the N-containing reactions. In a recent review, Kobayashi et al.[5] also reported considerable discrepancy between the experiments and the predictions of the laminar burning velocity of $\mathrm{NH}_{3}$-air flames. 
This work is aimed at characterizing the combustion behavior of $\mathrm{NH}_{3} / \mathrm{DMM}$ blends over a wide range of conditions to test their applicability in modern combustion devices. To achieve these goals, measurements of laminar burning velocity for various $\mathrm{NH}_{3} / \mathrm{DMM}$ mixtures were carried out in a Constant Volume Spherical Vessel (CVSV). To understand the combustion behavior of $\mathrm{NH}_{3} / \mathrm{DMM}$ blends, a chemical kinetic model was constructed from Shrestha et al. [31] for $\mathrm{NH}_{3}$ base model, and the DMM sub-mechanism was added from Sun et al. [32]. Such studies of $\mathrm{NH}_{3}$ in dual-fuel combustion applications offer a fundamental combustion database for stepwise movement towards the low-carbon mobility future. Therefore, this work aims at improving the $\mathrm{NH}_{3}$ oxidation model by validating against the newly measured experimental data on the laminar flame speeds of $\mathrm{DMM} / \mathrm{NH}_{3}$ blends over a wide range of conditions.

\section{Experimental Setup}

The Constant Volume Spherical Vessel, CVSV, at KAUST (shown in Fig. 1) has an inner diameter of $330 \mathrm{~mm}$ and is equipped with two orthogonal pairs of quartz windows of $120 \mathrm{~mm}$ in diameter. The initial temperature of the mixture was recorded at two locations inside the vessel to ensure the thermal homogeneity of the mixture. Mixtures of ammonia ( $>99.98 \%$ purity), DMM ( $>99.5 \%$ purity), and dry air were prepared in the vessel according to the required partial pressures of the gaseous components. The dry air on a molar basis has a composition of $20.947 \% \mathrm{O}_{2}$, $78.084 \% \mathrm{~N}_{2}, 0.9 \%$ argon, and the remaining $0.1 \%$ are carbon dioxide, helium, neon, and hydrogen. The required amount of liquid DMM was injected inside the vessel using a gas-tight micro-syringe under vacuum, which immediately evaporates to the required partial pressure of DMM. Then gaseous ammonia was added followed by dry air. A pressure transducer (Keller; PAA-33X, which guarantees the accuracy of $0.005 \%$ in full scale) fitted to the vessel was used to monitor the partial pressure of the reactants during the mixture preparation as well as the initial mixture pressure 
before ignition. The maximum deviation between the initial mixture pressure inside the vessel and the required initial pressure was about $3 \%$. Before filling the CVSV, it was evacuated up to 0.001 $\mathrm{MPa}$ and purged with nitrogen to remove combustion residuals. Mixtures were ignited by using two spark electrodes (1.2 $\mathrm{mm}$ diameter), forming a V-shape configuration at the center of the vessel with a $1 \mathrm{~mm}$ gap. An average spark ignition energy was set to $24 \mathrm{~mJ}$. To ensure mixture homogeneity, CVSV is equipped with a fan located inside the vessel at the top flange. The fan was stopped approximately $45 \mathrm{~s}$ before ignition event to prevent any perturbation to the flame propagation. Clear flame propagation was recorded by schlieren photography with a high-speed camera (Photron; FastCam Ultima APX 120K) at 4000 fps and $512 \times 512$ pixels with a spatial resolution of approximately $315 \mu \mathrm{m} /$ pixel. The uncertainty of the counted pixels associated with each flame radius in the digital photos is \pm 1 pixel. This leads to a maximum uncertainty of $\pm 1.6 \%$ at the minimum flame radius of $20 \mathrm{~mm}$ and a minimum uncertainty of $\pm 0.7 \%$ at the maximum flame radius of $45 \mathrm{~mm}$. For a given condition, the measurements were repeated three to five times to check the repeatability of the data. The experimental data were found within the estimated experimental uncertainty ( $97 \%$ confidence level). The unstretched laminar burning velocity and burned Markestein length (described in Section 3.2) were determined as the average value of the results obtained from each experiment. The experimental fluctuation was defined as the difference between the maximum and minimum values of the experimental results.

The uncertainties in the laminar burning velocity measurements using the spherical flame outward propagation include the confinement effect, flame instability, ignition energy, buoyancy, and nonlinearity of the stretch rate-flame speed relationship [33]. Uncertainties in the measured laminar burning velocity were between $\pm 0.6 \mathrm{~cm} / \mathrm{s}$ and $\pm 1.3 \mathrm{~cm} / \mathrm{s}$, depending on the equivalence ratio and $\mathrm{DMM} / \mathrm{NH}_{3}$ mixture fraction. The maximum observed flame radius was around $45 \mathrm{~mm}$; 
thus, there was no pressure rise in the chamber. This radius gives a volume of the burned gases less than $2.1 \%$ of the CVSV volume, which avoids pressure rise and confinement effects [34]. The uncertainty in the measured laminar burning velocity accounts for the all sources of experimental errors, based on the combination of the experimental and statistical errors (with a $0.97 \%$ selfconfidence calculated from Student's law and standard deviation). In the current study, the uncertainty was estimated using the Taylor Series Method of uncertainty propagation, as described in [35]. In addition, the appearance of the flame (shown in Section 3) does not show any tendency to become unstable within the acquired flame radius; thus, the flame instability did not contribute to the experimental uncertainty. The ignition energy effect and the suitability of the nonlinear or linear methodologies for the flame speed-stretch rate relationship were carefully considered to avoid their impacts on the reported data (discussed in Section 3.2). The effect of buoyancy is noticeable for the flames with laminar burning velocity $<15 \mathrm{~cm} / \mathrm{s}$ [36]. In the current blends, few flames had unstretched laminar burning velocity $<15 \mathrm{~cm} / \mathrm{s}$, furthermore, these flames did not show any change in the flame symmetry or upward drifting during their propagation, see Section 3.1. Consequently, the buoyancy effects were considered insignificant in this study. Details of radiation-induced uncertainty of the experimental setup can be found elsewhere [37,38], which showed the uncertainty having a value of $<4 \%$ for the lowest measured laminar burning velocity at $14-15 \mathrm{~cm} / \mathrm{s}$. 


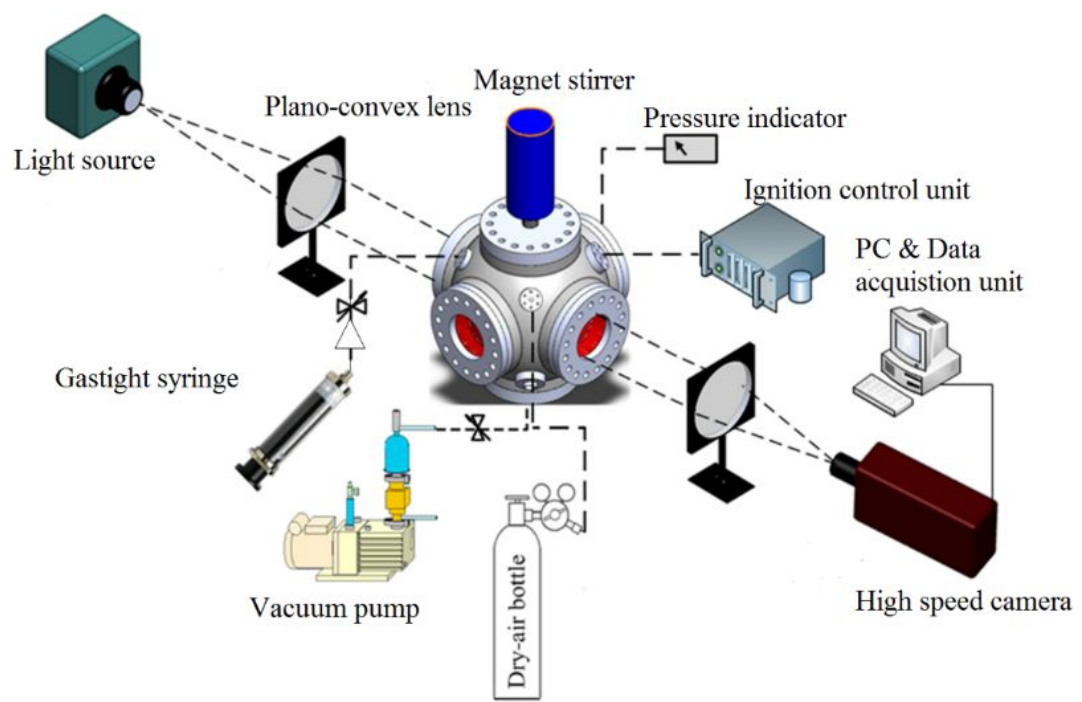

Figure 1. Schematic diagram of the experimental setup

For the spherically propagating laminar flames, the stretched propagating flame speed, $S_{n}$, is evaluated as $S_{n}=d R_{f} f d t$, where $R_{f}$ is the schlieren flame radius, and $t$ is time. The spherical propagating flame is subjected to curvature or aerodynamic strains. Hence, $S_{n}$ represents the stretched laminar flame speed of a spherical flame and is dependent on the total stretch rate, $\kappa$. The total stretch rate in spherical flame, $\kappa$, is defined as the time change of flame area per unit area: $(1 / A)(d A / d t)=\left(2 / R_{f}\right) S_{n}$, where $A$ is the flame surface area. Various correlations between $S_{n}$ and $\kappa$ have been proposed to estimate the unstretched laminar burning velocity relative to the burnt gas, $S_{s}$, which enable the elimination of the effect of stretch by extrapolating $S_{n}$ to zero stretch rate [39]. The asymptotic analysis showed that the difference between the unstretched laminar burning velocity, $S_{s}$, and the stretched flame speed, $S_{n}$, is linearly proportional to the flame stretch rate as given by $S_{s}-S_{n}=L_{b} k[40]$, where the proportionality constant $L_{b}$ is the burned gas Markstein length. On the other hand, the nonlinear relationship [41] was found to be most appropriate for extracting 
$S_{s}$ from the measured data using the following correlation (section 3.2 will detail the selection of the methodology for the flame speed extrapolation):

$$
\left(\frac{S_{n}}{S_{s}}\right)^{2} \ln \left(\frac{S_{n}}{S_{s}}\right)^{2}=-2 \frac{L_{b} k}{S_{s}}
$$

In this correlation, $S_{s}$ and $L_{b}$ can be deduced from the linear extrapolation in a plot of $\ln \left(S_{n}\right)$ versus $\kappa / S_{n}^{2}$, with an intercept on the $\ln \left(S_{n}\right)$ axis equal to $\ln \left(S_{s}\right)$ and the slope of a value equal to $\left(-S_{s} L_{b}\right)$. After extracting $S_{s}$, the unstretched laminar burning velocity relative to the unburnt gas, $S_{L}$, is obtained by the mass balance over the unstretched flame as $S_{L}=S_{S} / \sigma$, where $\sigma$ is the expansion coefficient, i.e., the ratio of the unburnt mixture density, $\rho_{l}$, to the burnt gas density, $\rho_{b}$.

The laminar flame speed measurements were conducted on various $\mathrm{NH}_{3} / \mathrm{DMM}$ blends, where the DMM mole fraction in the blends, $\chi_{\mathrm{DMM}}$, was varied over $0.2,0.3,0.4$ and 0.6 . For these blends, the mixture equivalence ratio was varied from 0.8 to 1.3 while keeping the mixture temperature, $T_{i}$, and pressure, $P_{i}$, at $298 \pm 3 \mathrm{~K}$, and $0.10 \mathrm{MPa}$, respectively. The unburnt and burnt mixture properties are listed in Table 1 . The unburnt mixture density, $\rho_{u}$, and the burnt gas density, $\rho_{b}$, for the different blend at the various equivalence ratio, $\Phi$, are illustrated in Table 1 . The $\lambda, \mathrm{c}_{\mathrm{p}}, \alpha$, and $v$ are the thermal conductivity, specific heat at constant pressure, thermal diffusivity and kinematic viscosity, respectively. The combustion literature reported several definitions of an equivalent Lewis number for a mixture with two fuel components. The first formulation of the effective Lewis number introduced by law et al. [42], was based on the weighted average non-dimensional heat release of the two fuel components. The second formulation of the effective lewis number was derived based on a volumetric fraction-weighted average of the fuel diffusivities [43]. While the third definition was based on the volumetric fraction-weighted average formulation, see Muppala et al. [44]. Recently, Nicolas et al.[45] investigated the impacts of the previous formulations of the 
effective Lewis number on hydrogen/hydrocarbon/air mixture flames. They showed that the volumetric weighted average approach was found to be the most consistent for the tested hydrogen/hydrocarbon/air flames and leading to a qualitatively accurate prediction of both Markesten length sign and slope inversion. Thus, in the current study, Le number was evaluated using the average mole-weighted formula of the deficient reactants: $\left(\frac{\chi_{D M M} L e_{D_{M M}}+\chi_{N_{3}} L e_{N_{3}}}{\chi_{D M M}+\chi_{N_{3}}}\right)$, in this correlation, $\chi_{\mathrm{NH} 3}$ represents $\mathrm{NH}_{3}$ mole fraction in the blend [2, 46], which is similar to the volumetric fraction-weighted approach. Lewis numbers characterizing mixtures with a single fuel " $i$ ", were computed as: $L e_{i}=\frac{D_{T}}{D_{i m}} . \quad D_{T}$ is the mixture thermal diffusivity and $D_{i m}$, is the mass diffusivity of the deficient reactant ' $i$ ' relative to the gas mixture. The mixture thermal diffusivity was calculated as: $D_{T}=\frac{\lambda}{\rho_{u} c_{p}}$, with $\lambda$ and $C_{p}$ being the mixture-averaged thermal conductivity and specific heat, respectively. The mixture thermal conductivity and ordinary diffusion coefficients of the species were obtained using the full multicomponent transport model, solving the so called L matrix. Subsequently, the mass diffusion coefficients of each species of interest $\left(\mathrm{DMM}, \mathrm{NH}_{3}\right.$, and $\mathrm{O}_{2}$ ) were evaluated as mixture-averaged diffusion coefficients into the mixture. The specific heat at constant pressure, $C_{p}$, was evaluated as the mass fraction-weighted: $C_{p}=\sum_{i=1}^{N} C_{p, i} Y_{i}$, with $Y_{i}$ and $C_{p, i}$ being the mass fraction and specific heat of the $\mathrm{i}^{\text {th }}$ species, respectively. As shown in Table $1, L e$ for lean mixtures is greater than unity which is found to increase with increasing $\chi_{\mathrm{DMM}}$, but it remains constant for rich mixtures.

Table 1: The unburnt and burnt mixture properties used in this study. The initial temperature and pressure of the mixture were $298 \mathrm{~K}$ and $0.1 \mathrm{MPa}$, respectively.

\begin{tabular}{|c|c|c|c|c|c|c|c|c|}
\hline$\chi_{\text {DMM }}$ & $\begin{array}{l}\Phi \\
--\end{array}$ & $\begin{array}{c}\rho_{\mathrm{u}} \\
\left(\mathrm{kg} / \mathrm{m}^{3}\right)\end{array}$ & $\begin{array}{c}\rho_{\mathrm{b}} \\
\left(\mathrm{kg} / \mathrm{m}^{3}\right)\end{array}$ & $\begin{array}{c}\lambda \times 10^{-3} \\
(\mathrm{~W} / \mathrm{mK})\end{array}$ & $\begin{array}{c}\mathrm{c}_{\mathrm{p}} \\
(\mathrm{J} / \mathrm{kg} / \mathrm{K})\end{array}$ & $\begin{array}{c}\alpha \times 10^{-5} \\
\left(\mathrm{~m}^{2} / \mathrm{s}\right)\end{array}$ & $\begin{array}{l}v \times 10^{-5} \\
\left(\mathrm{~m}^{2} / \mathrm{s}\right)\end{array}$ & $\begin{array}{l}\text { Le } \\
(--)\end{array}$ \\
\hline \multirow[t]{4}{*}{0.2} & 0.9 & 1.1711 & 0.1542 & 26.431 & 1102 & 2.064 & 1.475 & 1.162 \\
\hline & 1.0 & 1.1721 & 0.1472 & 26.428 & 1101 & 2.050 & 1.465 & -- \\
\hline & 1.1 & 1.1723 & 0.1457 & 26.425 & 1119 & 2.035 & 1.455 & 1.031 \\
\hline & 1.2 & 1.1731 & 0.1471 & 26.421 & 1127 & 2.022 & 1.445 & 1.026 \\
\hline
\end{tabular}




\begin{tabular}{ccccccccc} 
& 1.3 & 1.1733 & 0.1490 & 26.421 & 1135 & 2.009 & 1.435 & 1.021 \\
\hline 0.3 & 0.9 & 1.1961 & 0.1548 & 26.173 & 1092 & 2.030 & 1.454 & 1.252 \\
& 1.0 & 1.1984 & 0.1478 & 26.148 & 1100 & 2.012 & 1.442 & - \\
& 1.1 & 1.2007 & 0.1460 & 26.123 & 1107 & 1.995 & 1.430 & 1.031 \\
& 1.2 & 1.2030 & 0.1473 & 26.098 & 1115 & 1.978 & 1.418 & 1.026 \\
& 1.3 & 1.2052 & 0.1491 & 26.073 & 1122 & 1.962 & 1.407 & 1.021 \\
\hline 0.4 & 0.8 & 1.2088 & 0.1655 & 26.041 & 1078 & 2.027 & 1.455 & 1.342 \\
& 0.9 & 1.2130 & 0.1551 & 25.999 & 1086 & 2.006 & 1.441 & 1.330 \\
& 1.0 & 1.2171 & 0.1483 & 25.958 & 1093 & 1.986 & 1.427 & - \\
& 1.1 & 1.2211 & 0.1463 & 25.917 & 1100 & 1.926 & 1.414 & 1.031 \\
& 1.2 & 1.2251 & 0.1474 & 25.877 & 1107 & 1.949 & 1.401 & 1.026 \\
& 1.3 & 1.2289 & 0.1492 & 25.839 & 1114 & 1.931 & 1.388 & 1.021 \\
& & & & & & & & \\
\hline 0.6 & 0.8 & 1.2288 & 0.1656 & 25.841 & 1071 & 2.000 & 1.439 & 1.469 \\
& 0.9 & 1.2354 & 0.1555 & 25.778 & 1078 & 1.977 & 1.423 & 1.455 \\
& 1.0 & 1.2419 & 0.1490 & 25.716 & 1084 & 1.954 & 1.408 & - \\
& 1.1 & 1.2484 & 0.1468 & 25.655 & 1091 & 1.933 & 1.393 & 1.031 \\
& 1.2 & 1.2547 & 0.1476 & 25.596 & 1097 & 1.912 & 1.379 & 1.026 \\
& 1.3 & 1.2609 & 0.1493 & 25.539 & 1103 & 1.892 & 1.365 & 1.021 \\
\hline
\end{tabular}

\section{Results and Discussion}

\subsection{Flame appearance and observations}

Figure 2 illustrates the propagation of the spherical laminar flames corresponding to the various elapsed time after the ignition event for $\chi_{D M M}=0.2$ and 0.6 at the equivalence ratio $(\Phi)$ of 0.9 to 1.3 (see Fig. 2a and Fig. 2b, respectively). No flame instability was observed, which is true for all studied cases. However, at $\Phi=0.8$ and $\chi_{D M M}=0.2$ (not shown in Fig. 2), the hot spot generated by the spark was observed between the spark electrodes at $\mathrm{t}=0 \mathrm{~ms}$. But after a few milliseconds, the boundaries of the flame kernel become extinguished as a result of the high local stretch rate. Under these conditions, the flame kernel tends to readily quench due to low heat release from the chemical reaction. For $\chi_{D M M}=0.2$ and $\Phi=0.9$, the flame was found to be most susceptible to the buoyancy effects because it had the lowest flame propagation speed. The center of this flame was close to the spark electrodes up to the flame radius of $60 \mathrm{~mm}$ with no appreciable deformation of the flame appearance. This indicates that the buoyancy effect on the flame shape was negligible. 
As seen in Fig. 2a, after an elapsed time of $30 \mathrm{~ms}$, the flame radius for $\Phi=1.1$ was found to be larger than that of $\Phi=0.9$, and 1.3. The minor flame cracks observed at $\Phi=1.1$ and 1.3 for $\chi_{D M M}$ $=0.6$ are believed to be consequences of the large deposit ignition energy along with the thinner flame thickness at high $\chi_{D M M}$. In addition, these little observed cracks did not develop into more cracks at larger flame radius where the stretch rate decreases and its stabilizing influence is diminished. Clearly, increasing the mole fraction of $\chi_{D M M}$ increases the flame propagation speed (see images in Fig. 2a, and Fig. 2b for a given elapsed time, for example at $\mathrm{t}=20 \mathrm{~ms}$ ).

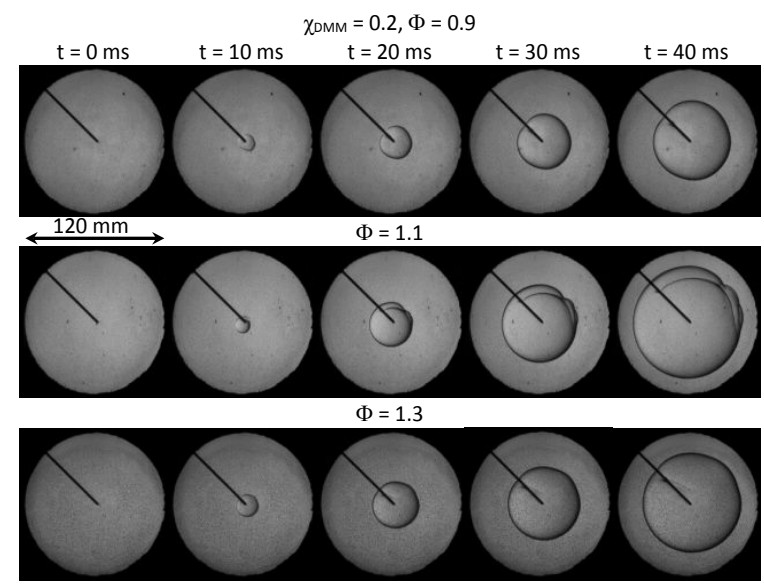

(a)

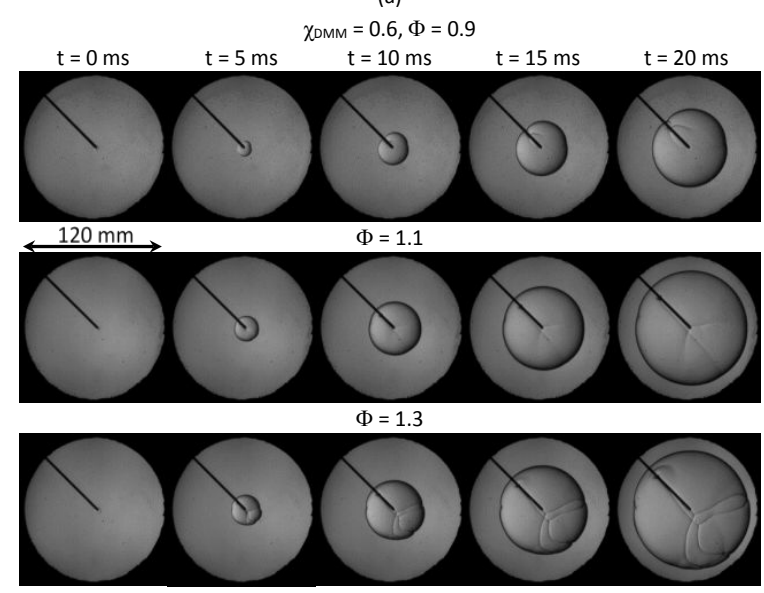

(b)

Figure 2. Schlieren images of $\mathrm{NH}_{3} / \mathrm{DMM}$ flames recorded at (a) $\chi_{D M M}=0.2$ and (b) $\chi_{D M M}=0.6$, for the equivalence ratio $(\Phi)$ of $0.9,1.1$ and 1.3 . 


\subsection{Laminar flame speed experimental data for $\mathrm{NH}_{3} / \mathrm{DMM}$ blends}

Figure 3 illustrates the typical behaviors of the stretched flame speed, $S_{n}$, and the flame stretch rate, $\kappa$, with the flame radius, $R_{f}$, for two flames with $\chi_{D M M}=0.3$ and 0.6 and various $\Phi$. In the CVSV, the elapsed time of the flame propagation can be subdivided into three regions: an ignition affected region, a stationary propagation region, and a chamber affected region. As shown in Figs. 3a-3b, $S_{n}$ exhibits excessively large values after spark ignition, associated with high flame curvature and hence stretch rates (see Figs. 3c-3d). Then both $S_{n}$ and $\kappa$ decrease sharply to minimum value due to the ignition transition from the deposited spark energy. This trend is more evident for lean flames $(\Phi=0.8$, and 0.9$)$ indicating that such flames are more prone to the stretch rate. The ignition transient regime develops into the stationary propagation regime, where $S_{n}$ eventually approaches a steady-state value, and $\kappa$ steadily decreases to roughly merge at higher values of $R_{f}$ (see Figs. 3c-3d). The development from the ignition regime to the stable regime transpires faster at higher $\chi_{D M M}$. The large inner diameter of CVSV relative to the schlieren imaging region minimizes the effect of the chamber confinement on the flame propagation as confirmed by the $S_{n}$ and $\kappa$ versus $R_{f}$ plots.
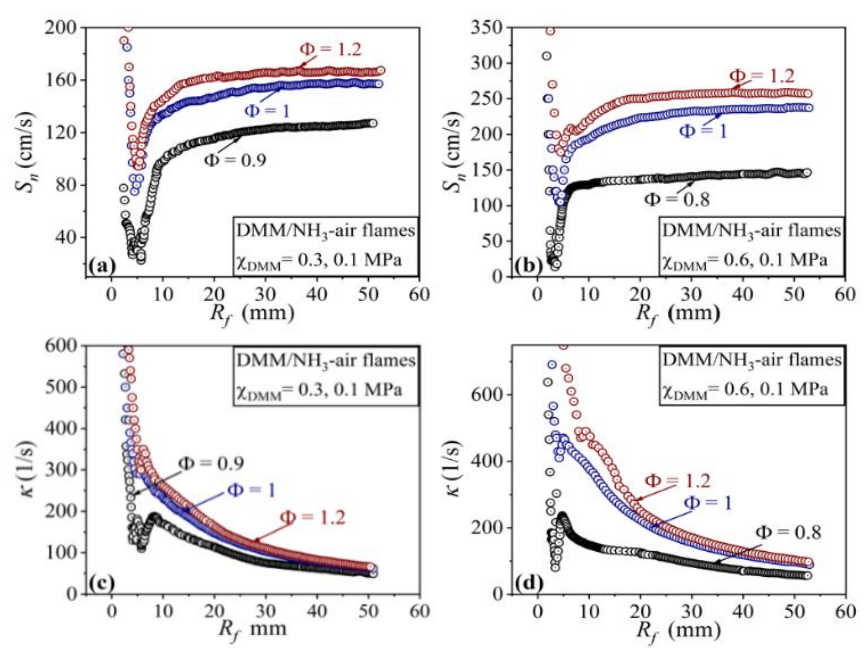

Figure 3. Variations of the stretched flame speed, $S_{n}$, and the flame stretch rate, $\kappa$ with $R_{f}$ at $\chi_{D M M}$ $=0.3$ and 0.6 for various $\Phi$ 
The transition from the spark energy deposition to the steady flame propagation after ignition shows different trajectories depending on the flame conditions. This can be illustrated by plotting $S_{n}$ versus $\kappa$ for two flames at $\Phi=0.8$ and 1.2 , while keeping the same $\chi_{D M M}$ at 0.4 (see Fig. 4). For these flames, the Lewis number, $L e$, changes from 1.342 to 1.026 for $\Phi=0.8$ and 1.2 , respectively (see Table 1). As can be seen, $S_{n}$ versus $\kappa$ plot exhibits a ' $Z$ ' like trajectory for the lean mixture in contrary to the rich flames which follow nearly a linear path. Similar ' $Z$ ' like trajectory was reported for rich $\mathrm{CH}_{4} / \mathrm{NH}_{3}$-air flames [2], where $L \mathrm{e}$ was equal to 1.1 . The lower branch of this $\mathrm{Z}$ path stems from the influence of ignition; whereas the middle and upper branches are caused by the thermos-diffusive and radiative heat loss. Also, the energy deposited by the spark may partially affect the middle part of the trajectory [47]. Note that the nonlinear behavior of $S_{n}$ versus $\kappa$ transforms into linearity by increasing $\Phi$ from 0.8 to 1.2 . This change can be attributed to the combined effects of both the Lewis number and the preheat flame thickness. A detail discussion will follow in the next section.

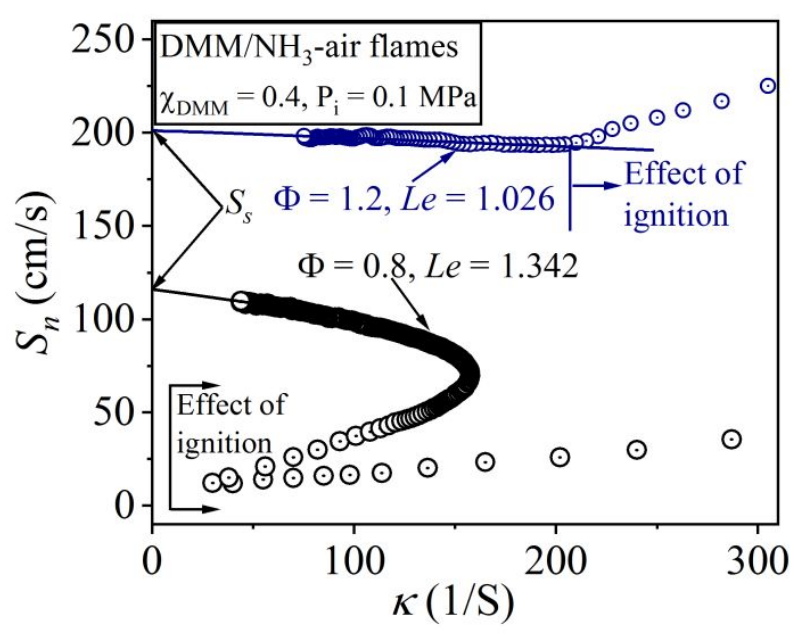

Figure 4. Stretched flame speed, $S_{n}$, versus flame stretch rate, $\kappa$, for two flames with different Lewis number, $L \mathrm{e}$. 
Only $R_{\mathrm{f}}$ values between $20 \mathrm{~mm}$ (to avoid the effect of ignition energy that was overdriving the flame) and $45 \mathrm{~mm}$ (to ensure that the recorded images within the isobaric region of the vessel pressure signal)were used to extract $S_{\mathrm{s}}$ (see Fig. 5) to reduce the uncertainties due to the stretch extrapolation. However, at least 50 data points are used to extract $S_{s}$. The ' $Z$ ' like trajectory behavior of $S_{n}-\kappa$ relationship was found to decrease as $\Phi$ increases which is true for both blends of $\chi_{\mathrm{DMM}}=0.3$ and 0.6 . Additionally, for a given $\Phi, S_{n^{-}} \kappa$ plot was observed to behave more linearly trajectory after ignition for higher $\chi_{\text {DMM }}$ flames. This is more obvious for the lean flames, e.g., $\Phi$ $=0.9$ (see Figs $5 \mathrm{a}-5 \mathrm{~b}$ ), indicating that the $\mathrm{NH}_{3}$ rich blends exhibit a more tendency to ' $\mathrm{Z}$ ' like trajectory in $S_{n}{ }^{-} \kappa$ relationship. Similar observations were reported for $\mathrm{CH}_{4} / \mathrm{NH}_{3}$ flames $[2,46]$. Therefore, the stretch effect needs to be eliminated by extrapolating the $S_{n}$ to zero stretch rate. Different stretch extrapolation relations have been proposed [48], and it is believed that the method for $S_{n^{-}} \kappa$ extrapolation is one of the major sources of uncertainties. As illustrated by Wu et al. [48], to reduce the uncertainty due to the extrapolation, the ratio of $2 L_{b, l i n} / R_{f, \text { mid }}$ should lie between -0.1 and 0.15 , where $L_{b, l i n}$ is the Markstien length deduced from the linear extrapolation, and $R_{f, \text { mid }}$ is the middle radius of the data under consideration. Thus, to limit the extrapolation effect, the mixture Lewis number should be around unity or to have a wide range of usable flame radii [38]. For the mixture blends of extreme Lewis number, i.e., the blend with $\chi_{D M M}=0.6$ and $\Phi=0.8$ and 1.2, the linear and non-linear extrapolation plots are presented in Fig. 5b. For the full radius range, i.e., $20-45 \mathrm{~mm}$, the values of $2 L_{b, \text { lin }} / R_{f, \text { mid }}$ are 0.09 and 0.04 for $\Phi=0.8$ and 1.2 , respectively which lie within the range of Wu's criterion. This indicates that with the current large vessel, the linear and nonlinear extrapolations provide negligible difference. Since the nonlinear model is expected to be more general than the linear model and can be applied for arbitrary mixtures with 
wide range of Le number, the nonlinear correlation was applied in this work to deduce the unstretched laminar burning velocity and burned gas Markestein length.
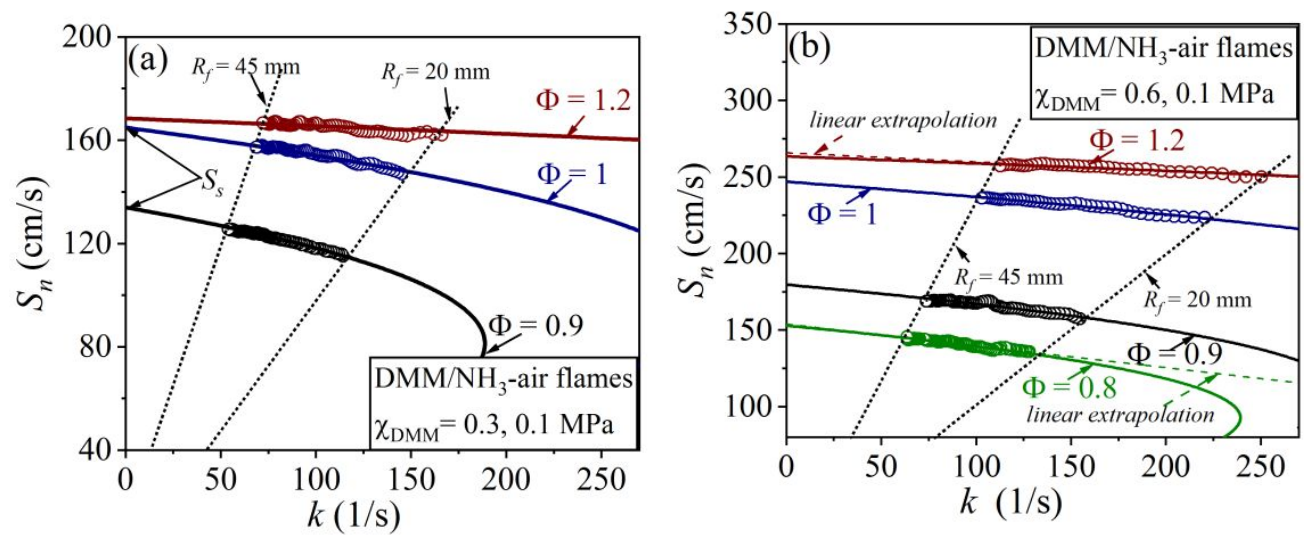

Figure 5. Stretched laminar flame speed, $S_{n}$, versus $\kappa$ for different $\Phi$ : (a) at $\chi_{D M M}=0.3$, (b) at $\chi_{D M M}=0.6$. The symbols represent the measured data, while the curves are the nonlinear extrapolation of the measurements, and the dashed lines show the linear extrapolation at $\chi_{D M M}=$ 0.6 , for $\Phi=0.8$ and 1.2.

The sensitivity of $S_{n}$ to the stretch rate at the different blend ratios is evaluated by measuring the burned gas Markestein length, $L_{b}$. Figure 6 plots the variation of $L_{b}$ with $\Phi$ for the different $\mathrm{DMM} / \mathrm{NH}_{3}$ blends. For comparison, the values reported by Hayakawa et al. [1] for neat $\mathrm{NH}_{3}$-air flames are also plotted. As seen, $\mathrm{DMM} / \mathrm{NH}_{3}$ blends show a different trend than the neat $\mathrm{NH}_{3}$-air flames. Unlike neat $\mathrm{NH}_{3}$, the $L_{b}$ values (all positive) for $\mathrm{DMM} / \mathrm{NH}_{3}$ blends show a steeper decline with increasing $\Phi$. For neat $\mathrm{NH}_{3}, L_{b}$ values are negative for $\Phi<0.9$, which keeps increasing to positive values as the mixture gets richer. Another notable difference was found with the Lewis number $(L \mathrm{e})$. For lean $\mathrm{NH}_{3}$ flames, $L$ e was found to be less than unity and increased to greater than unity for rich mixture; whereas $L$ e values are higher than 1 for all $\mathrm{DMM} / \mathrm{NH}_{3}$ blends investigated here. Thereby, for the neat $\mathrm{NH}_{3}$ /air flames, the burned gas Markstein lengths at lean mixtures were 
negative because temperature and burning velocity of stretched flames increase due to the thermosdiffusive effects. As indicated in Table 1, Le values of lean mixtures are significantly larger for high $\chi_{\mathrm{DMM}}$. For rich mixtures, the variation in Le with $\chi_{\mathrm{DMM}}$ is not noticeable. This explains the variation of $L_{b}$ with $\Phi$ observed, which shows a decrease in $L_{b}$ with increasing $\Phi$. For example, when Le is close to unity (rich mixtures in Table 1), the flame stretch, i.e., the thermos-diffusive effects, do not significantly alter the propagating flame speed, $S_{n}$. Figure 6 further illustrates the variation of $L_{b}$ with $\chi_{\mathrm{DMM}}$. For lean flames, $L_{b}$ increases with increasing $\chi_{\mathrm{DMM}}$. On the contrary, the rich flames show a negligible variation of $L_{b}$ with $\chi_{\mathrm{DMM}}(0.3-0.6)$. However, the rich flames of $\chi_{\mathrm{DMM}}=0.2$ show relative higher $L_{b}$ values than that of $\chi_{\mathrm{DMM}}>0.3$ blends.

Earlier studies $[49,50]$ have shown that $L_{\mathrm{b}}$ is a function of $L \mathrm{e}$ (Lewis number), $\sigma$ (thermal expansion coefficient), Ze (the Zeldovich-number) and $\delta_{l}$ (the preheat flame thickness), as given by the relationship: $L_{\mathrm{b}}=\delta_{l}\left[f_{1}(\sigma)+Z \mathrm{e}\left(L_{\mathrm{e}}-1\right) f_{2}(\sigma)\right]$. Here, $f_{1}$ and $f_{2}$ are functions of $\sigma$ and have positive values. The first term in this relationship is always positive and is important in equidiffusive mixtures. The second term accounts for thermos-diffusive effects on the flame speeds of those mixtures with non-equidiffusive, and it takes negative (positive) values for flames with Le less (greater) than unity. For the $\mathrm{DMM} / \mathrm{NH}_{3}$ blends considered here, $\sigma$ does not vary significantly. For the lean mixtures, it appears that the positive dependence of $L_{b}$ on $\chi_{\mathrm{DMM}}$ stems from the combined effects of $\delta_{l}, Z$ e, and $L e$. Figure 7 illustrates the variation of both $\delta_{L}$ and $Z e$ with $\Phi$ for various $\chi_{\text {DMM }} . \delta_{L}$ is calculated as $\left(\lambda / \rho_{u} C_{p} S_{L}\right)$, where $\lambda$ and $C_{p}$ are the thermal conductivity and the specific heat capacity at a constant pressure of the mixture, respectively. Zeldovich-number, $Z e$, which may express the sensitivity of the flame speed to the variation in the maximum flame temperature [51], is defined as $4\left(T_{b}-T_{u}\right) /\left(T_{b}-T^{o}\right)$, where $T_{b}$ and $T_{u}$ are the burned and unburned temperatures, while $T^{o}$ is the inner layer temperature $[51,52]$. Within the temperature profile of 
premixed flames, the inner layer temperature marks the transition from inert preheat zone to the reaction zone, and therefore, it is the point where the second derivative vanishes and the slope is maximum. Mixture properties, $T_{b}$, and $T^{b}$ used for estimating $\mathrm{Ze}$ and $\delta_{L}$ were calculated using the composite chemical kinetic model used for simulation of the laminar burning velocity and premixed flames while keeping the same grid constraints, as described in section 3.3. The Zeldovich number could also be evaluated as $E\left(T_{b}-T_{u}\right) / R T_{b}^{2} ; E$ is the mixture activation energy, and $\mathrm{R}$ is the universal gas constant [53]. $E$ can be determined from the relationship $E / R=-2 d \ln \left(\rho_{u}\right.$ $\left.S_{L}\right) / d\left(1 / T_{b}\right)$ [54]. Evaluation of $E / R$ requires the calculation of $\ln \left(\rho_{u} S_{L}\right)$ at different $T_{b} . T_{b}$ is estimated by a small variation in $T_{u}$ for each $\chi_{D M M}[55]$. Here, the two formulae to evaluate Ze yield nearly identical values.

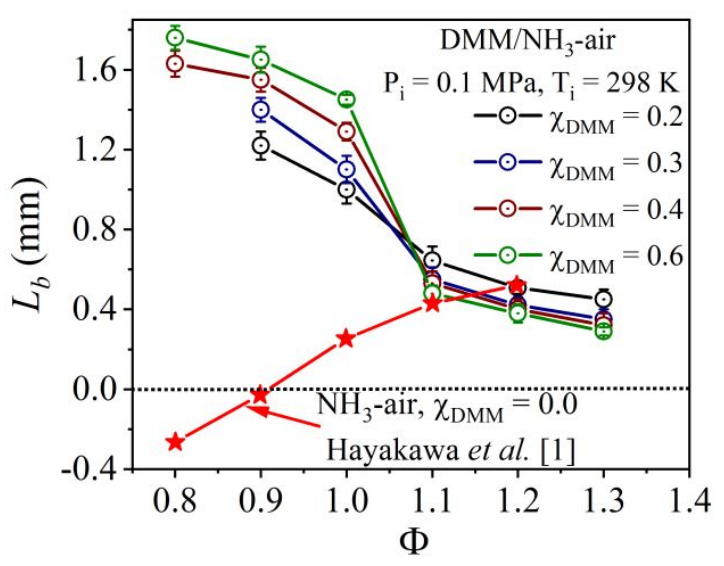

Figure 6. Relationship between $L_{b}$ and $\Phi$ for different $\mathrm{DMM} / \mathrm{NH}_{3}$ blends and neat $\mathrm{NH}_{3}$ flames [1]. 

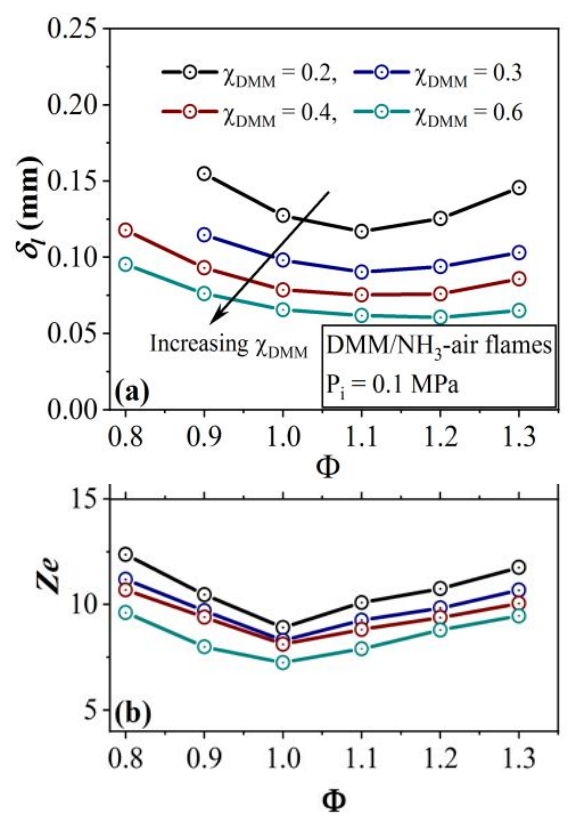

Figure 7. Equivalence ratio $(\Phi)$ dependence of the preheating zone thickness, $\delta_{l}(\mathrm{a})$, and Zel'dovich number, $\mathrm{Ze}$ (b) for various $\mathrm{NH}_{3} / \mathrm{DMM}$ blends.

As illustrated in Fig. $7 \mathrm{a}, \delta_{l}$ decreases with increasing $\chi_{D M M}\left(\right.$ i.e., less $\mathrm{NH}_{3} \%$ ) for a given $\Phi$, and the thinnest $\delta_{l}$ occurs at $\Phi=1.1$ except for $\chi_{\mathrm{DMM}}=0.6$, where $\delta_{l}$ remains nearly constant after $\Phi=1.1$. $Z e$ also decreases with $\chi_{\text {DMM }}$ with a minimum value occurring at $\Phi=1$ (see Fig. $7 \mathrm{~b}$ ). According to the previous $L_{b}$ relationship, the increment in both $\delta_{l}$ and $Z e$ will promote the effect of a non-unity $L e$ to yield higher values of $L_{b}$. Such combined effects are more prominent for the leaner blends, where both $\delta_{l}$ and $Z e$ in addition to $L e$, have higher values. Interestingly, $L_{b}$ is found to increase with $\chi_{\mathrm{DMM}}$ even though the values for both $\delta_{L}$ and $Z e$ show a decline with increasing $\chi_{\mathrm{DMM}}$ for a given $\Phi$ under lean conditions (see Fig. 6). This indicates that Le has a more dominant effect on $L_{\mathrm{b}}$ than both $\delta_{L}$ and $Z e$ combined. The effect of the $Z e$ on $L_{b}$ is negligible for the rich mixtures. Besides, Le is close to unity for rich mixtures $\left(\chi_{\mathrm{DMM}}=0.3\right.$ to 0.6$)$ which reduces the impact of both $\delta_{L}$ and $Z e$ on $L_{\mathrm{b}}$ for these blends. However, higher values of $L_{b}$ are observed for richer blends with $\chi_{\mathrm{DMM}}=0.2$ in contrast to the blends with $\chi_{\mathrm{DMM}}>0.2$ (see Fig.6). For this particular blend, $\delta_{l}$ and 
Ze show a relative increase at higher $\Phi$ relative to the other rich mixture blends as illustrated in Fig. 7.

\subsection{Laminar burning velocity prediction from chemical kinetic simulations}

A robust chemical kinetic model is not available in the literature for $\mathrm{DMM} / \mathrm{NH}_{3}$ blends. Therefore, a composite kinetic model was constructed by combining the base mechanism for $\mathrm{NH}_{3}$ from Shrestha et al. [31], and DMM sub-mechanism from Sun et al. [32]. Shrestha et al. [31] tested the robustness of their kinetic model for $\mathrm{C}, \mathrm{H}, \mathrm{N}, \mathrm{O}$ system by validating against several experimental targets, e.g., laminar burning velocities, ignition delay times, speciation from jetstirred and flow reactors, and premixed-flame data [56]; whereas Sun et al. [32] developed the mechanism for the oxidation of poly(oxymethylene) dimethyl ethers (which also includes DMM) and validated against their measurements of the laminar burning velocities and speciation data in low-pressure premixed flames. Simulations of the laminar burning velocity and the premixed flames were performed with the PREMIX module in ANSYS CHEMKIN-Pro package. Up to 300 grids were used to obtain converged solutions with the constraints for GRAD and CURV as 0.1 and 0.01 , respectively. Figure 8a shows the comparison between the model predictions and experimental data for the laminar burning velocity $\left(S_{L}\right)$ of DMM/NH 3 blends. The measured $S_{L}$ of neat DMM/air-flame [57] is also presented. In this work, additional measurements were carried out for neat DMM-air flames to compare our data with the well-established data from Gillespie et al. [57]. As can be seen, the experimental data from present work is in excellent agreement with that of Gillespie et al. [57] indicating the reliability of the current work (see ref. [58] for further illustration of our laminar flame speed for neat DMM data at elevated temperatures and pressures). The present kinetic model performs excellently in predicting $S_{L}$ for neat DMM for all the equivalence ratio investigated. However, the predictions for $\mathrm{DMM} / \mathrm{NH}_{3}$ blends are somewhat 
overpredicted. The overprediction in the worst-case scenario is $\sim 20 \%$ for the leans flames, in particular for $\chi_{\mathrm{DMM}}=0.6$ flames. The discrepancies between the model prediction and the measurements are highest for $\chi_{\mathrm{DMM}}=0.6$ cases; the possible cause of this higher discrepancy is explained in detail with the help of reaction flow analysis in Section 3.4. The model predictions show better agreement with the data for stoichiometric and rich mixtures $\left(_{\text {DMM }}=0.2,0.3\right.$, and 0.4). Interestingly, the experimental $S_{L}$ data for the rich $\mathrm{NH}_{3} / \mathrm{DMM}$-air mixtures do not exhibit the same degree of attenuation with $\Phi$ as that of the lean mixtures. Overall, the model follows the experimental trend very well of increasing laminar burning velocities with the increase of $\chi_{D M M}$. The attempts to investigate neat $\mathrm{NH}_{3}$ flames were futile because the small flame kernel generated after the spark ignition could not sustain. Since for neat $\mathrm{NH}_{3}$ flames, and $L e<1$, the extinguishing of the flame kernel may be attributed to the limited spark energy and heat loss.

Figure $8 \mathrm{~b}$ compiles literature $S_{L}$ data $[1,28,59-65]$ for neat $\mathrm{NH}_{3}$-air mixtures and compares with the present model predictions. The model prediction is reasonably good for lean-to stoichiometric $\mathrm{NH}_{3} /$ air flames at 1 atm and $298 \mathrm{~K}$. For rich conditions $(\Phi>1.1)$, the model predicts somewhat higher values of $S_{L}$. However, there is a considerable discrepancy among the fuel-rich experimental data, particularly for mixtures with $\Phi>1.1$. Most of the experimental data exhibit a maximum value of $S_{L}$ near $\Phi=1.1$ for $\mathrm{NH}_{3}$-air mixtures. This phenomenon is well captured by the current model. Furthermore, in Fig. 8 it is seen that the predicted laminar burning velocity for neat $\mathrm{NH}_{3}$ towards lean conditions are slower compared to most of the experimental data; however, this trend is reversed when $\mathrm{NH}_{3}$ is blended with DMM. Blending $\mathrm{NH}_{3}$ with the DMM significantly affects some of the key radical pool concentration in the flame (see Figure S1of the radical pool profiles in the in supporting information) which primarily controls the system reactivity. 
Since nitrogen chemistry is mostly controlled by the more complex radicals pool (e.g. $\mathrm{N}_{x} \mathrm{H}_{y}$ radicals), the reverse trend on the laminar burning velocity (towards the lean side) could be due to an unbalance in the radical pool in the blended system. This can be further supported using temperature versus equivalence ratio illustration (see Figure S2 of adiabatic flame temperature versus $\Phi$, in the supporting information). It can be observed that the temperature difference in the flames between the neat $\mathrm{NH}_{3}$ and the blended system is higher towards the lean side compared to the rich side. As stated earlier, the current model predicts the laminar burning velocity of the neat DMM very well than DMM/ $\mathrm{NH}_{3}$ blends. This may highlight the importance of some of the cross elementary reactions between nitrogen and carbon family, which may be missing in the current kinetic model. This warrants further optimization/investigation of the composite model, which is currently underway.

The heat release during the oxidation of fuel directly controls the adiabatic flame temperature. Since DMM has a higher lower heating value than that of ammonia, one expects that $\mathrm{DMM} / \mathrm{NH}_{3}$ blends will have the higher adiabatic-flame temperature with increasing $\chi_{D M M}$ (see Fig. S2). Consequently, the laminar burning velocities are higher for larger $\chi_{D M M}$ in $\mathrm{DMM} / \mathrm{NH}_{3}$ blends. Note that the burning velocity is directly proportional to the square root of the product of the thermal diffusivity $(\alpha)$ and the rate of reaction (RR) $\left(S_{L} \alpha \sqrt{\alpha \cdot \mathrm{RR}}\right.$ [66]), and RR is a strong function of the flame temperature. Clearly, the DMM content in $\mathrm{DMM} / \mathrm{NH}_{3}$ blends strongly impact the flame temperature and hence the laminar flame speed. The thermal diffusivity $(\alpha)$ does not change much for varying $\chi_{D M M}$ (see Table 1). Therefore, its impact on the adiabatic flame temperature for varying $\chi_{D M M}$ is not significant. 

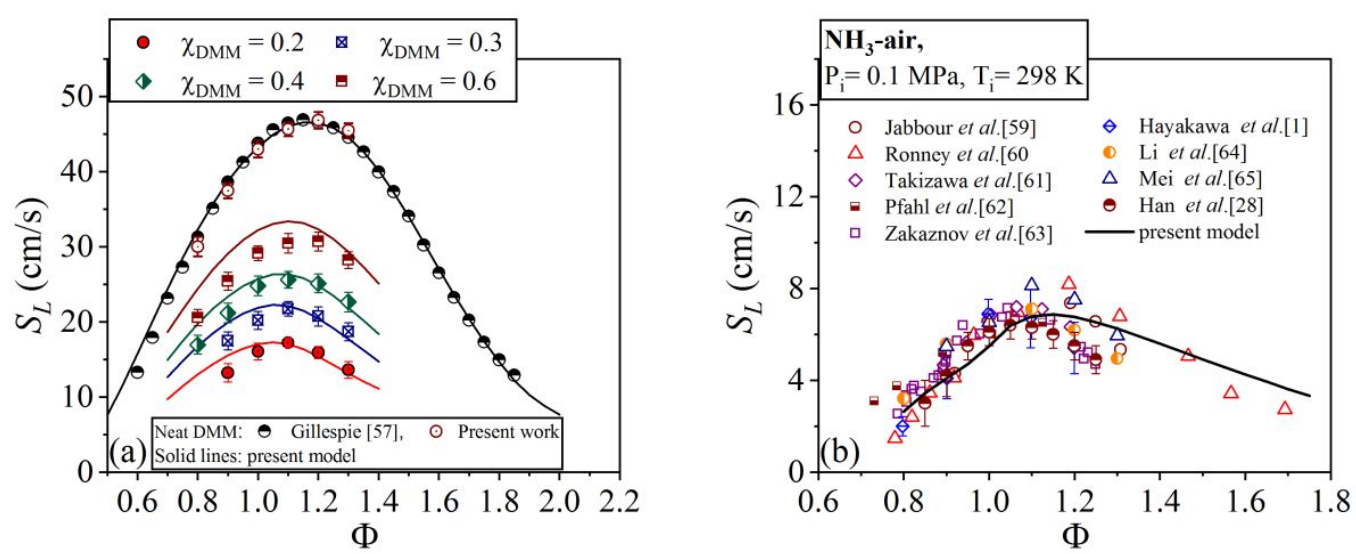

Figure 8. Comparison of the measured $S_{L}$ with simulated values: (a) for various $\mathrm{DMM} / \mathrm{NH}_{3}$ blends, neat DMM, and (b) for neat $\mathrm{NH}_{3}$. The error bars represent the uncertainty in our measurements (experiimental methdologies: heat flux methode [28], [57] - constnat volume chamber vessel [1], [59-62] [64-65], and cylinderical flow tube [63]).

Figure 9a plots the degree of enhancement of the laminar burning velocity of ammonia by blending with various mole fractions of $\mathrm{DMM}$ and $\mathrm{CH}_{4}$. The $S_{L}$ data for $\mathrm{CH}_{4} / \mathrm{NH}_{3}$ blends were taken from Han et al. [28]. The addition of ignition promoter (DMM or $\left.\mathrm{CH}_{4}\right)$ causes roughly a linear increase in $S_{L}$ for a given equivalence ratio between 0.9 and 1.1. Evidently, DMM is a better ignition promoter as it greatly enhances $S_{L}$ compared to $\mathrm{CH}_{4}$ for a given condition. To quantify the degree of enhancement, we used the normalized enhancement factor $\xi_{E}$ [28], which is defined as: $\xi_{E}, \%=\left[S_{L}\left(\chi_{M}, \Phi\right)-S_{L, \mathrm{NH} 3}(\Phi)\right] / S_{L, \mathrm{NH} 3}(\Phi)$. Here, $S_{L, \mathrm{NH} 3}(\Phi)$ and $S_{L}\left(\chi_{M}, \Phi\right)$ are the laminar burning velocities of $\mathrm{NH}_{3}$ /air flames and the $\mathrm{NH}_{3}-\mathrm{M}$ blends $\left(\mathrm{M}=\mathrm{DMM}\right.$ or $\left.\mathrm{CH}_{4}\right)$ for a given $\Phi$, respectively. Figure $9 \mathrm{~b}$ illustrates the enhancement factor $\xi_{E}$ versus $\Phi$ for $\chi_{D M M}$ or $\chi_{C H 4}=0.2$ and 0.6. Again, DMM shows promising results with a higher degree of enhancement as compared to $\mathrm{CH}_{4}$ for all $\Phi$. The $\xi_{E}$ for $\chi_{D M M}=0.2$ comes nearly equal to that of $\chi_{C H 4}=0.6$ for a given $\Phi$ between 0.9 and 1.1, and $\xi_{E}$ values for DMM are even higher for $\Phi>1.1$ (see Fig. 9b). Interestingly, methane shows big enhancement effects on the lean side, whereas DMM displays high degree of 
enhancement for both lean and rich mixtures (for $\chi_{D M M}=0.6, \xi_{E}=540 \%$ and $470 \%$ for $\Phi=0.8$ and 1.3 , respectively).

For $\chi_{D M M}=0.2$, the enhancement factor remains nearly constant at $\sim 200 \%$ for $0.9 \leq \Phi \leq 1.1$. Relative to methane, the presence of activated methylene groups next to oxygen atoms $\left(-\mathrm{O}-\mathrm{CH}_{2}-\right)$ in the chemical structure of DMM leads to the formation of hydroperoxides in the early stage of combustion (see Fig. S1 in SM). These hydroperoxides decompose into OH radicals, which are one of the key radicals for the decomposition of $\mathrm{NH}_{3}$ and $\mathrm{DMM}$ as well as the radical derivatives. Also, the $\left(-\mathrm{CH}_{2} \mathrm{O}-\right)$ chain leads to the enhancement of the carbon flux to $\mathrm{CH}_{2} \mathrm{O}$ and fewer to carbon atoms ending up in $\mathrm{CH}_{3}$, which is not the case of the methane chemistry blended with $\mathrm{NH}_{3}$; where all the $\mathrm{CH}_{4}$ is consumed first by $\mathrm{H}$ abstraction to form $\mathrm{CH}_{3}$.
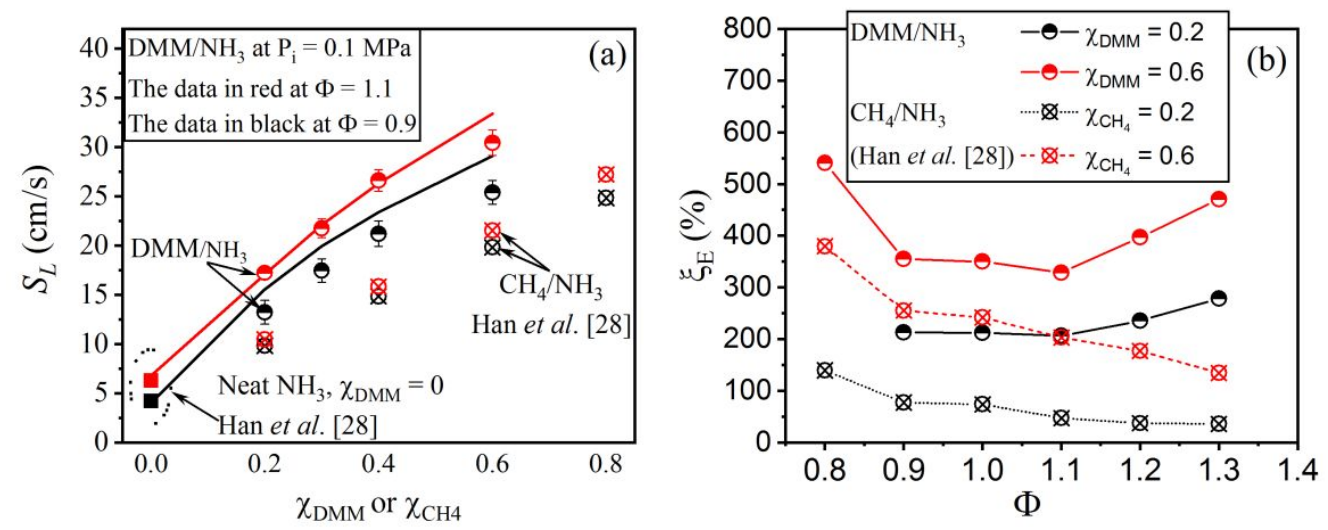

Figure 9. (a) Variation of $S_{L}$ with $\chi_{D M M}$ or $\chi_{C H 4}$ relative to neat $\mathrm{NH}_{3}$ (solid lines are the simulation results), (b) enhancement factor, $\xi_{E}$, versus $\Phi$ for a given $\chi_{D M M}$ or $\chi_{C H 4}$

\subsection{Ammonia-DMM flame chemistry}

Despite some discrepancy between the model predictions and measurements for the blended system, the present model accurately follows the experimental trend highlighting its capability in describing the flame kinetics. To explore the essential reaction pathways for laminar burning 
velocity prediction that could be of interest for future study for developing a comprehensive model, a reaction flow analysis and sensitivity analysis are conducted and discussed. For brevity, we will analyze the stoichiometric $\mathrm{NH}_{3} / \mathrm{DMM}$-air flames, where we also observed the highest discrepancy between model prediction and experiment for $\chi_{D M M}=0.6$. The discussion will be based on the results obtained from the current composite kinetic model. The major reaction pathways are identified by employing integrated mass flux analyses based on $\mathrm{C}$-atoms and $\mathrm{N}$-atoms for stoichiometric $\mathrm{NH}_{3} / \mathrm{DMM}$ blends of two cases: $\chi_{D M M}=0.2$ and 0.6 (see Fig. 10). Reaction path analyses (Fig. 10a) reveals that DMM mainly undergoes $\mathrm{H}$-atom abstraction at the terminal carbon atom by reactive $\mathrm{H}$ and $\mathrm{OH}$ species mostly to form $\mathrm{CH}_{3} \mathrm{OCH}_{2} \mathrm{OCH}_{2}$ via, reactions $\mathrm{R} 1$ and $\mathrm{R} 2$, respectively.

$\mathrm{CH}_{3} \mathrm{OCH}_{2} \mathrm{OCH}_{3}(+\mathrm{H}, \mathrm{OH})=\mathrm{CH}_{3} \mathrm{OCH}_{2} \mathrm{OCH}_{2}\left(+\mathrm{H}_{2}, \mathrm{H}_{2} \mathrm{O}\right)$

As the $\chi_{D M M}$ in the blend increases, more reactive intermediate species $(\mathrm{H}, \mathrm{O}$, and $\mathrm{OH})$ are formed (see Fig. 11). Not surprisingly, a higher yield of $\mathrm{CH}_{3} \mathrm{OCH}_{2} \mathrm{OCH}_{2}$ radicals is achieved for higher mole fraction of DMM, e.g., $82 \%$ and $91 \%$ for $\chi_{D M M}=0.2$ and 0.6 , respectively. Regardless of $\chi_{D M M}$, all $\mathrm{CH}_{3} \mathrm{OCH}_{2} \mathrm{OCH}_{2}$ radicals undergo thermal unimolecular dissociation to form $\mathrm{CH}_{3} \mathrm{OCH}_{2}$ (67\%) and $\mathrm{CH}_{2} \mathrm{O}(33 \%)$. The formed $\mathrm{CH}_{3} \mathrm{OCH}_{2}$ radical will readily decompose to $\mathrm{CH}_{2} \mathrm{O}(50 \%)$ and $\mathrm{CH}_{3}(48 \%)$. Also, a portion of $\mathrm{CH}_{3}$ reacts with $\mathrm{O}$-atom to form $\mathrm{CH}_{2} \mathrm{O}$ via reaction $\mathrm{R} 3$, and a small fraction of $\mathrm{CH}_{3}$ reacts with $\mathrm{NO}_{2}$ to form $\mathrm{CH}_{3} \mathrm{O}$ through reaction $\mathrm{R} 4$. However, it is interesting to see that as $\chi_{D M M}$ increases from 0.2 to $0.6, \mathrm{HO}_{2}$ radical also participates in converting $\mathrm{CH}_{3}$ to $\mathrm{CH}_{3} \mathrm{O}$ via reaction $\mathrm{R} 5$, which is not seen for $\chi_{D M M}=0.2$.

$\mathrm{CH}_{3}+\mathrm{O}=\mathrm{CH}_{2} \mathrm{O}+\mathrm{H}$

$\mathrm{CH}_{3}\left(+\mathrm{NO}_{2}, \mathrm{HO}_{2}\right)=\mathrm{CH}_{3} \mathrm{O}(+\mathrm{NO}, \mathrm{OH})$ 
The importance of $\mathrm{HO}_{2}$ radical at higher $\chi_{D M M}$ is shown as the reaction $\mathrm{R} 5$ can be linked to the path $\mathrm{NNH} \longrightarrow \mathrm{N}_{2}$ (see Fig. 10b). At $\chi_{D M M}=0.2 \mathrm{NNH}$ is mainly decomposed to $\mathrm{N}_{2}+\mathrm{H}$ via thermal dissociation channel, however, at $\chi_{D M M}=0.6 \mathrm{NNH}$ reacts mostly with $\mathrm{O}_{2}$ to form $\mathrm{N}_{2}+\mathrm{HO}_{2}$ and minor contribution is via thermal dissociation channel and vice versa. The $\mathrm{HO}_{2}$ radical formed (at $\chi_{D M M}=0.6$ ), reacts with $\mathrm{CH}_{3}$ via reaction $\mathrm{R} 5$ to give $\mathrm{CH}_{3} \mathrm{O}$, which further thermally dissociates to give $\mathrm{CH}_{2} \mathrm{O}+\mathrm{H}$. In this sequence, the less reactive $\mathrm{HO}_{2}$ radical is consumed to form more reactive $\mathrm{H}$-atom. The reaction $\mathrm{NNH}+\mathrm{O}_{2}=\mathrm{N}_{2}+\mathrm{HO}_{2}$ becomes vital in producing the $\mathrm{HO}_{2}$ radical, and the reaction rate of this reaction certainly controls its formation. This partially explains why the present model predicted higher flame velocity at the stoichiometric condition $\chi_{D M M}=0.6$ compared to $\chi_{D M M}=0.2$ and the reaction rate of this reaction requires further investigation based on the present analysis. However, no attempt is made to investigate the sensitivity of the reaction rate of this reaction ( $\mathrm{NNH}+\mathrm{O}_{2}=\mathrm{N}_{2}+\mathrm{HO}_{2}$ ) on model prediction, which is beyond the scope of the present study. This also further leads to the conclusion as to why the current model predicted higher flame velocity at lean condition (excess oxygen) for all the $\chi_{D M M}$ investigated compared to rich condition (see Figure 8). As can be seen in Fig. 10a, higher hydrocarbon intermediates $\left(C_{2}\right.$ species) are formed following the reaction sequence: $\mathrm{DMM} \rightarrow \mathrm{CH}_{3} \mathrm{OCH}_{2} \mathrm{OCH}_{2} \rightarrow \mathrm{CH}_{3} \mathrm{OCH}_{2} \rightarrow \mathrm{CH}_{3}\left(+\mathrm{CH}_{3}\right)$. Unsurprisingly, the formation of $\mathrm{C}_{2}$ species is favoured by $4 \%$ more for $\chi_{D M M}=0.6$ as compared to $\chi_{D M M}=0.2$, leading to the conclusion that higher DMM content in the blend favours higher hydrocarbon formation. Formaldehyde $\left(\mathrm{CH}_{2} \mathrm{O}\right)$ follows the usual route by reacting with $\mathrm{H}$ atom and $\mathrm{OH}$ radical to form formyl radical ( $\mathrm{HCO}$ ) which subsequently undergoes thermal dissociation to form $\mathrm{CO}$ and $\mathrm{H}$ atom. The formed $\mathrm{CO}$ then reacts with $\mathrm{OH}$ radicals to form $\mathrm{CO}_{2}$ (see the reaction sequences R6-R9 below).

$\mathrm{CH}_{2} \mathrm{O}(+\mathrm{H}, \mathrm{OH})=\mathrm{HCO}\left(+\mathrm{H}_{2}, \mathrm{H}_{2} \mathrm{O}\right)$ 
$\mathrm{HCO}(+\mathrm{M})=\mathrm{H}+\mathrm{CO}(+\mathrm{M})$

$\mathrm{CO}+\mathrm{OH}=\mathrm{CO}_{2}+\mathrm{H}$

Figure. $10 \mathrm{~b}$ shows the reaction path analysis for $\mathrm{NH}_{3}$ consumption. The reaction is initiated by $\mathrm{H}-$ abstraction with $\mathrm{OH}$ radicals and $\mathrm{H}$-atom to form amidogen $\left(\mathrm{NH}_{2}\right)$ radical (reactions $\mathrm{R} 10$ and $\left.\mathrm{R} 11\right)$.

$\mathrm{NH}_{3}(+\mathrm{H}, \mathrm{OH})=\mathrm{NH}_{2}\left(+\mathrm{H}_{2}, \mathrm{H}_{2} \mathrm{O}\right)$

(R10, R11)

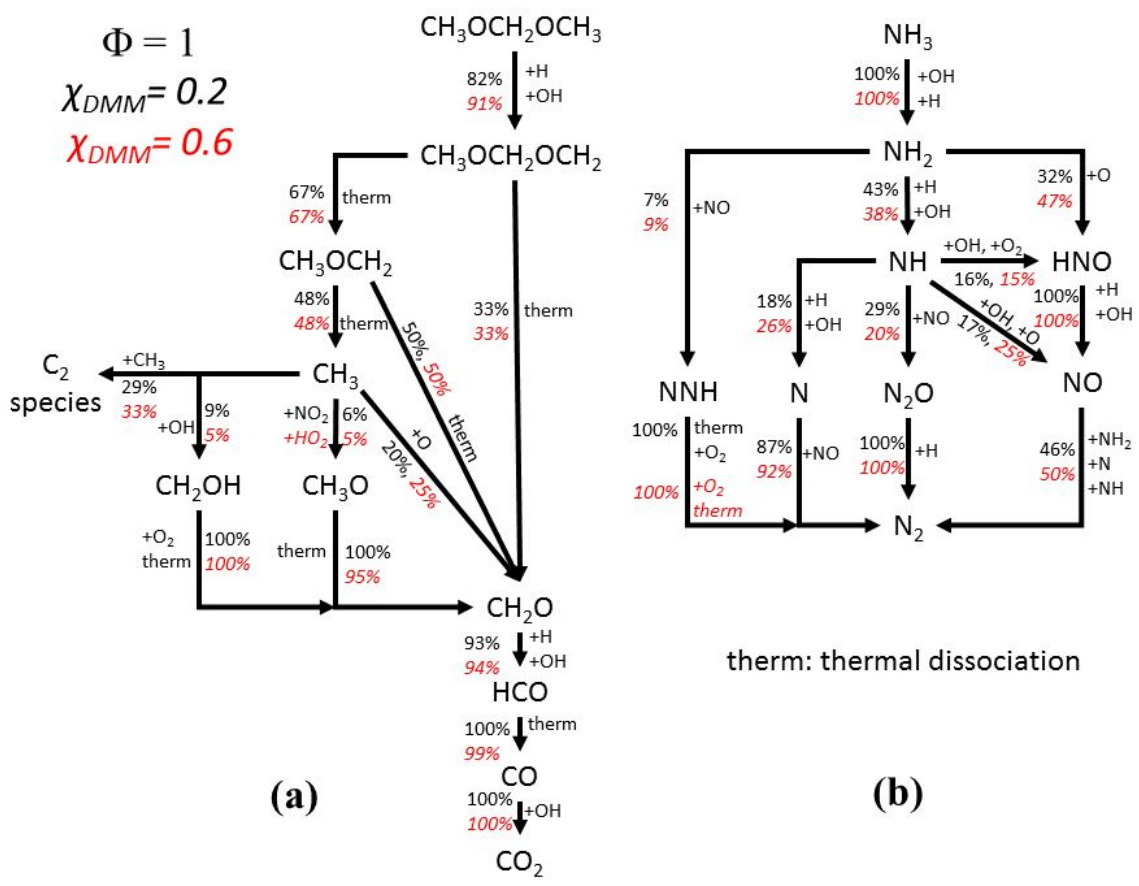

Figure 10. Integrated reaction flow analysis for the degradation of DMM based on C-atom (a) and for $\mathrm{NH}_{3}$ based on $\mathrm{N}$-atom (b) of the stoichiometric $\mathrm{DMM}-\mathrm{NH}_{3}$ flames at $\chi_{D M M}=0.2$ and 0.6 using the current composite model. The radicals indicated along the arrows are ordered from top to bottom according to their contribution to the particular reaction pathway.

Consecutive reactions of $\mathrm{NH}_{2}$ with $\mathrm{OH}$ and $\mathrm{H}$ yield $\mathrm{NH}$, whereas its reaction with $\mathrm{O}$ atom generates HNO radical (see reaction sequences R12-R15). The flow analysis reveals that the pathway leading to $\mathrm{HNO}$ is favoured more at higher DMM content in the blend. For example, increasing $\chi_{D M M}$ from 0.2 to 0.6 , HNO formation path is favoured $15 \%$ more, and the reaction pathway leading to imidogen radical $(\mathrm{NH})$ is inhibited by $5 \%$. This observation is also in line with the sensitivity plot 
shown in Fig. 12, where R12 shows the highest negative sensitivity. The reaction flow analysis (Fig. 10b) also indicates that a small fraction of $\mathrm{NH}_{2}$ reacts with $\mathrm{NO}$ to form $\mathrm{NNH}(7 \%$, and $9 \%$ for $\chi_{D M M}=0.2$ and 0.6 , respectively). This chain propagating reaction $\mathrm{NH}_{2}+\mathrm{NO}=\mathrm{NNH}+\mathrm{OH}(\mathrm{R} 15)$ appears among the most sensitive reactions for the laminar burning velocity (see Fig. 12).

$\mathrm{NH}_{2}(+\mathrm{H}, \mathrm{OH})=\mathrm{NH}\left(+\mathrm{H}_{2}, \mathrm{H}_{2} \mathrm{O}\right)$

$\mathrm{NH}_{2}+\mathrm{O}=\mathrm{HNO}+\mathrm{H}$

$\mathrm{NH}_{2}+\mathrm{NO}=\mathrm{NNH}+\mathrm{OH}$

Imidogen (NH radical) further undergoes several reaction channels (R16-R24) to finally yield $\mathrm{N}_{2}$. One possible route occurs via $\mathrm{H}$-atom abstraction of $\mathrm{NH}$ radicals by $\mathrm{H}$ and $\mathrm{OH}$, forming $\mathrm{N}$ atoms which eventually lead to $\mathrm{N}_{2}$ by reacting with $\mathrm{NO}$. In another route, $\mathrm{NH}$ can also react with $\mathrm{OH}$ and $\mathrm{O}_{2}$ to form $\mathrm{HNO}$ which can react with $\mathrm{OH}$, and $\mathrm{H}$ to form $\mathrm{NO}$, and $\mathrm{NO}$ can eventually yield $\mathrm{N}_{2}$ via reactions $\mathrm{R} 22, \mathrm{R} 23$, and $\mathrm{R} 24$. The reaction of $\mathrm{NH}$ radical with $\mathrm{NO}$ forming $\mathrm{N}_{2} \mathrm{O}$ is also a major channel for $\mathrm{NH}$ loss, reaction (R25). The $\mathrm{N}_{2} \mathrm{O}$ formed exclusively goes to $\mathrm{N}_{2}$ by reacting with $\mathrm{H}-$ atom $\left(\mathrm{N}_{2} \mathrm{O}+\mathrm{H}=\mathrm{N}_{2}+\mathrm{OH}\right)$.

$\mathrm{NH}\left(+\mathrm{OH}, \mathrm{O}_{2}\right)=\mathrm{HNO}(+\mathrm{H}, \mathrm{O})$

$\mathrm{NH}(+\mathrm{OH}, \mathrm{O})=\mathrm{NO}\left(+\mathrm{H}_{2}, \mathrm{H}\right)$

$\mathrm{HNO}(+\mathrm{H}, \mathrm{OH})=\mathrm{NO}\left(+\mathrm{H}_{2}, \mathrm{H}_{2} \mathrm{O}\right)$

$\mathrm{NO}\left(+\mathrm{NH}_{2}, \mathrm{~N}, \mathrm{NH}\right)=\mathrm{N}_{2}\left(+\mathrm{H}_{2} \mathrm{O}, \mathrm{O}, \mathrm{OH}\right)$

(R22, R23, R24)

$\mathrm{NH}+\mathrm{NO}=\mathrm{N}_{2} \mathrm{O}+\mathrm{H}$ 
The model suggests that cross-reactions between the carbon and nitrogen family plays a minor role. For example, reaction $\mathrm{CH}_{3}+\mathrm{NH}_{2}=\mathrm{CH}_{3} \mathrm{NH}_{2}$ contributes $\sim 1 \%$ and $\sim 2 \%$ of $\mathrm{NH}_{2}$ consumption for $\chi_{D M M}=0.2$ and 0.6 , respectively, and reaction $\mathrm{CH}_{3}+\mathrm{NH}=\mathrm{CH}_{2} \mathrm{NH}+\mathrm{H}$ contributes $\sim 2 \%$ and $5 \%$ for $\chi_{D M M}=0.2$, and 0.6, respectively, for $\mathrm{NH}$ loss (not shown in Fig. 10). This may indicate that the interactions between $\mathrm{C}$ and $\mathrm{N}$ containing species are insignificant for the prediction of the laminar burning velocity and the flame structure. The sensitivity analysis displayed in Fig. 12 further justifies this argument.

Therefore, the oxidation of $\mathrm{NH}_{3} / \mathrm{DMM}$-air blends can be understood as parallel oxidations processes of the individual fuel components. However, in the process of dual-fuel oxidation, both components share the same $\mathrm{OH}, \mathrm{H}$, and $\mathrm{O}$ radical pool, thereby influencing the chemistry of DMM and $\mathrm{NH}_{3}$ indirectly. These parallel oxidation processes are in line with the reactions flow analyses of $\mathrm{NH}_{3} / \mathrm{CH}_{4}$-air flames at $\Phi=1$, undertaken by Okafor et al.[2]. For these $\mathrm{NH}_{3}$-dual fuel systems, similar reactions involving $\mathrm{OH}, \mathrm{H}$, and $\mathrm{O}$ species govern the kinetics, and hence they will have a significant influence on the laminar burning velocity. To explore the impact of $\chi_{D M M}$ on these key radicals, $\mathrm{OH}, \mathrm{O}, \mathrm{H}$, and $\mathrm{CO}$ radicals and temperature profiles were computed for the un-stretched adiabatic $\mathrm{DMM} / \mathrm{NH}_{3}$-air flames at $\Phi=1$ and $\chi_{D M M}=0.2,0.6$ (see Fig. 11). Here, the x-axis represents the computational domain. As seen, the mole fractions of all radicals decrease with decreasing $\chi_{D M M}$ (increasing $\mathrm{NH}_{3} \%$ ). In addition to the decline of the radical concentrations, the mole fraction profiles are also shifted towards the post-reaction zone for low $\chi_{D M M}$, which is also evident in the temperature profile. The relatively low flame speed for low $\chi_{D M M}$ can be attributed to the decrease in the temperature, mainly in the reaction zone. Therefore, the overall reactivity may slow down by the enhanced chain-terminating reactions stemming from $\mathrm{NH}_{3}$ chemistry. An increase in $\chi_{D M M}$ promotes the reactivity as demonstrated by the chain branching reaction, 
$\mathrm{CO}+\mathrm{OH}=\mathrm{CO}_{2}+\mathrm{H}$, which is the second most sensitive reaction in positive direction influencing $S_{L}$, and its influences increase with $\chi_{D M M}$ (see Fig. 12).

Figure 12 shows the top 15 sensitive reactions for the un-stretched laminar burning velocity of $\mathrm{DMM} / \mathrm{NH}_{3}$-air flame at $\Phi=1$, and various $\chi_{D M M}$. For the sake of comparison, the sensitive reactions of neat $\mathrm{NH}_{3}$-air flames are also presented. In all cases, the chain branching reaction $\left(\mathrm{O}_{2}+\mathrm{H}=\mathrm{OH}+\mathrm{O}\right)$ appears to be the most sensitive reaction. For neat $\mathrm{NH}_{3}$, the most influential reactions for $S_{L}$, through controlling $\mathrm{H}$ and $\mathrm{OH}$ radical concentrations, include R15, R20, R21, R22 and R26 (see Fig. 12a).

$\mathrm{NO}+\mathrm{H}(+\mathrm{M})=\mathrm{HNO}+\mathrm{M}$

From nitrogen chemistry, the chain propagating reaction, R15 appears to be the second most crucial reaction affecting the radical concentration after $\mathrm{O}_{2}+\mathrm{H}=\mathrm{OH}+\mathrm{O}$ reaction, whereas reactions R20, R21, and R22 show negative influence on the radical pool $[2,46]$. Reaction R26 does not show sensitivity towards $\mathrm{DMM} / \mathrm{NH}_{3}$ blends; however, it is the third most sensitive reaction (in a positive direction) for neat $\mathrm{NH}_{3}$ flame (see Fig. 12a-b). For the neat ammonia flame, reaction $\mathrm{R} 26$ shows a positive influence on $S_{L}$, where $\mathrm{HNO}$ radical is produced via the recombination of $\mathrm{NO}$ and $\mathrm{H}$-atom. However, the high $\mathrm{HNO}$ concentration may also promote the rate of $\mathrm{H}$-atom and $\mathrm{OH}$ radical consumption through the reactions of $\mathrm{R} 20$ and $\mathrm{R} 21$. This is in line with the sensitivity analysis where these reactions ( $\mathrm{R} 20$ and $\mathrm{R} 21$ ) have a negative impact on the laminar burning velocity. The same effect has been noticed for reaction R14. Though R14 produces H-atom, it exerts a negative impact on the flame speed through increased production of HNO radicals.

Figure $12 \mathrm{~b}$ illustrates the sensitivity analysis for $\mathrm{DMM} / \mathrm{NH}_{3}$ blends. Some reactions, e.g., R14, $\mathrm{R} 15$, and $\mathrm{R} 20$, appear to be sensitive for both neat $\mathrm{NH}_{3}$ and $\mathrm{DMM} / \mathrm{NH}_{3}$ blends which influence $\mathrm{H}$, 
$\mathrm{OH}$ and $\mathrm{O}$ radical pool, and promote the production of HNO. In addition, R16 and R18 also appear to be sensitive reactions for $\chi_{D M M}=0.2$ blend. These reactions form HNO and NO radicals which have a negative influence on $\mathrm{OH}$ radical concentration, and thereby on $S_{L}$. Reaction R14 displays the highest sensitivity in the negative direction, but its sensitivity decreases with the increase in $\chi_{D M M}$. The production of HNO via R14 and R16 enhances the negative effect on the flame speed via R20.

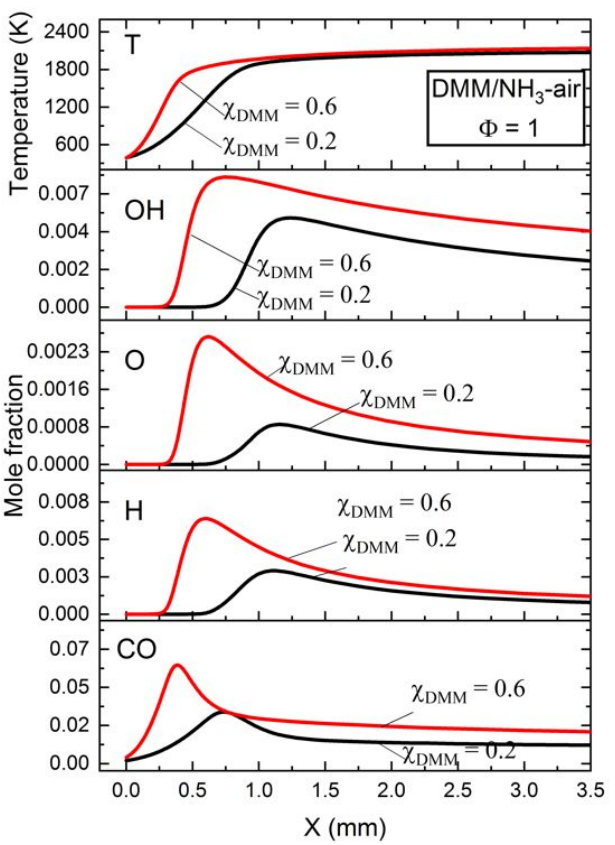

Figure 11. Temperature, and $\mathrm{OH}, \mathrm{O}, \mathrm{H}$ and $\mathrm{CO}$ radicals profiles for unstretched adiabatic $\mathrm{DMM} / \mathrm{NH}_{3}$-air flames at $\Phi=1$ and $\chi_{D M M}=0.2$ and 0.6 


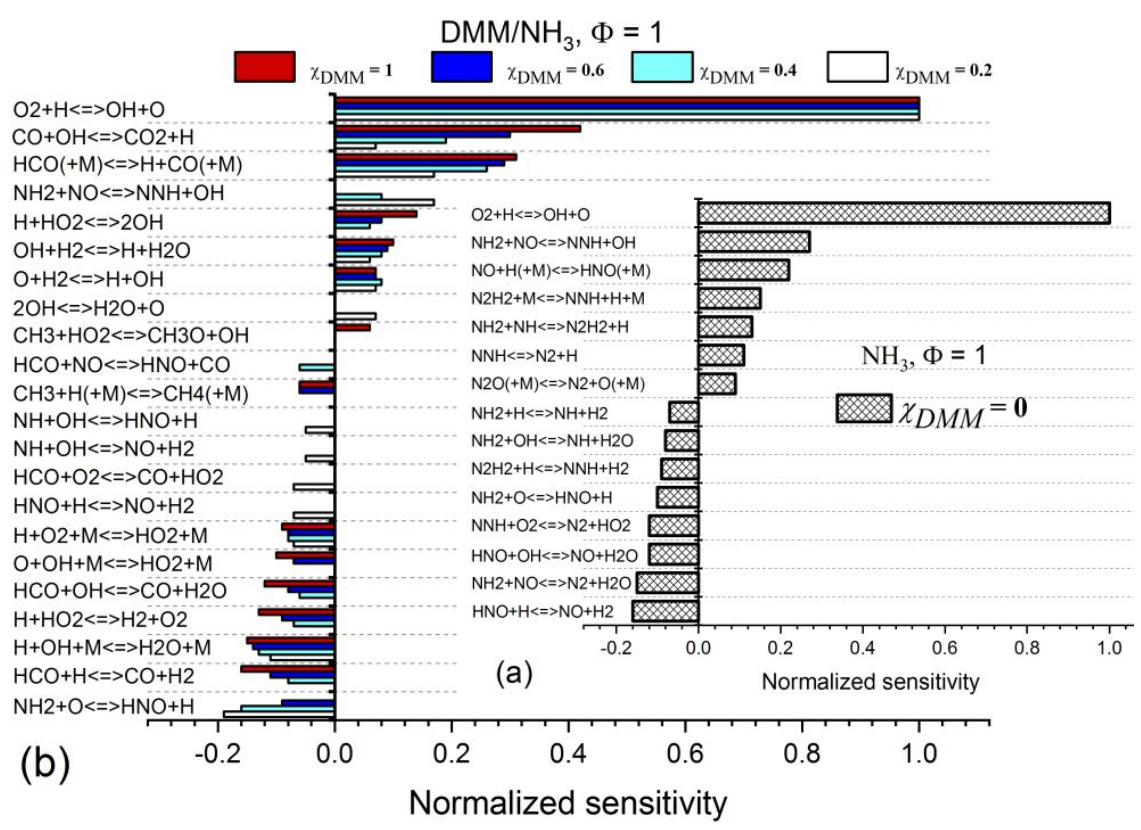

Figure 12. First-order normalized sensitivity of unstretched laminar burning velocity of stoichiometric: (a) $\mathrm{NH}_{3}$-air flames and (b) $\mathrm{NH}_{3} / \mathrm{DMM}$-air flames at various $\chi_{D M M}$. Positive sensitivity means that the reactions enhance the flame speed, and the negative sensitivity indicates that the reaction retards the flame speed.

As shown in Fig. 12b, the impact of the reactions from the nitrogen chemistry decreases with increasing $\chi_{D M M}$. For high $\chi_{D M M}$, DMM chemistry dominates by enhancing the flame speed of the blends via the core of $\mathrm{H}_{2} / \mathrm{CO}$ mechanism. As can be seen, $\mathrm{CO}+\mathrm{OH}=\mathrm{CO}_{2}+\mathrm{H}(\mathrm{R} 9)$, and $\mathrm{HCO}(+\mathrm{M})$ $=\mathrm{H}+\mathrm{CO}(+\mathrm{M})(\mathrm{R} 8)$ are the second and the third most sensitive reactions. Reaction $\mathrm{R} 8$ facilitates $\mathrm{H}$-atom production, and at the same time, it also promotes $\mathrm{CO}$ production. The formed $\mathrm{CO}$ reacts with $\mathrm{OH}$ radicals via $\mathrm{R} 9$ to produce more $\mathrm{H}$-atoms, which eventually enhances the flame speed. Reactions of $\mathrm{H}$ atoms with $\mathrm{HCO}\left(\mathrm{HCO}+\mathrm{H}=\mathrm{CO}+\mathrm{H}_{2}\right)$ and $\mathrm{OH}\left(\mathrm{H}+\mathrm{OH}+\mathrm{M}=\mathrm{H}_{2} \mathrm{O}+\mathrm{M}\right)$ are the second and the third most sensitive reactions in the negative direction. These are termination reactions and hence retard the flame speed. As seen in Fig. 11, the temperature begins to rise as $\mathrm{CO}$ starts to evolve in the system, revealing that the reactions involving $\mathrm{CO}$ are more sensitive for the temperature profile. In $\mathrm{CO} / \mathrm{NH}_{3}$-air mixtures with low $\chi_{\mathrm{NH} 3}$, Han et al. [28] showed that $\mathrm{H}$-atoms, formed by the decomposition of $\mathrm{NH}_{3}$, were found to enhance the combined $\mathrm{CO}$ oxidation and 
$\mathrm{H}_{2} / \mathrm{O}_{2}$ mechanisms by the increase of $\mathrm{H}$ and $\mathrm{OH}$ radical pools which led to the rapid increase of $S_{L}$. Their findings can be integrated into the current outcome where blends with higher $\chi_{D M M}$ produce a higher yield of $\mathrm{CO}$ at early times, which then expedites the flame speed (see Fig. 11). However, at low $\chi_{D M M}$, the shortage of $\mathrm{H}$ and $\mathrm{OH}$ radical pools and low $\mathrm{CO}$ concentration prevents early CO initiation, which explains the observed trend of decreasing $S_{L}$ with the increase of $\chi_{\mathrm{NH} 3}$. Therefore, the reactions of the carbon family are more important for expediting the laminar flame speed of the studied blends. As expected, the sensitivities of N-containing reactions are significantly decreased for $\chi_{\mathrm{DMM}}>0.2$ blends. Furthermore, it may be observed that the reactions involving $\mathrm{HO}_{2}$ radical show increased sensitivity with the increase of $\chi_{\mathrm{DMM}}$ (see Fig. $12 \mathrm{~b}$ ). The reason may be due to the presence of activated methylene group bound to the oxygen atoms (-O$\mathrm{CH}_{2}-$ ) in DMM, which leads to the formation of hydroperoxy alkyl radical in the early stage of the combustion as pointed out by Shrestha et al. [67].

A close inspection of Fig. 8 revealed that rich mixtures show less attenuation in $S_{L}$ as compared to the lean mixtures. This observation can be explained with the aid of Fig. 13, where the mole fraction profiles of $\mathrm{OH}, \mathrm{O}, \mathrm{H}$ and $\mathrm{CO}$ radicals are presented for $\Phi=1.2$. The decreased concentration of $\mathrm{OH}$ and $\mathrm{O}$ for rich flames, as opposed to the stoichiometric mixture, is not surprising. However, rich flames $(\Phi=1.2)$ show a significant increase of $\mathrm{CO}$ and $\mathrm{H}$ concentration as compared to that for $\Phi=1$ (see Fig. 11 and 13). For the rich mixtures, $\mathrm{CO}+\mathrm{OH}=\mathrm{CO}_{2}+\mathrm{H}(\mathrm{R} 9)$ plays a crucial role in enhancing the flame speed. 


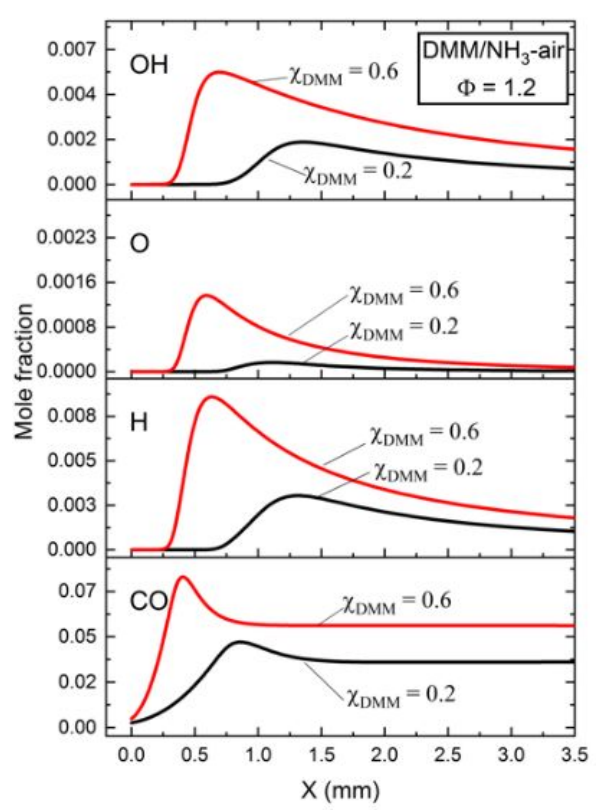

Figure 13. $\mathrm{OH}, \mathrm{O}, \mathrm{H}$, and $\mathrm{CO}$ radicals profiles for unstretched adiabatic $\mathrm{DMM} / \mathrm{NH}_{3}$-air flames for $\Phi=1.2$, and $\chi_{D M M}=0.2$ and 0.6

Figure 14 shows sensitivity analysis for the unstretched laminar burning velocity for various $\mathrm{DMM} / \mathrm{NH}_{3}$ flames at $\Phi=1.2$. As seen, $\mathrm{HCO}(+\mathrm{M})=\mathrm{H}+\mathrm{CO}(+\mathrm{M})$ appears to be the second most sensitive reaction in the positive direction followed by the $\mathrm{CO}+\mathrm{OH}$ reaction. Our reaction path analysis reveals that $\mathrm{HCO}(+\mathrm{M})=\mathrm{H}+\mathrm{CO}(+\mathrm{M})$ is the dominant path for the formyl radical consumption. A similar conclusion was made by earlier studies [68,69] indicating that the net $\mathrm{HCO}$ to $\mathrm{CO}$ conversion facilitates the $\mathrm{H}$-atom radical production, and hence promotes the chain branching reactions. This explains the observed higher concentrations of $\mathrm{CO}$ and $\mathrm{H}$ radicals for rich $\mathrm{NH}_{3}$-DMM flames, and thus their effects on the enhancement of laminar flame speed $\left(S_{L}\right)$. 


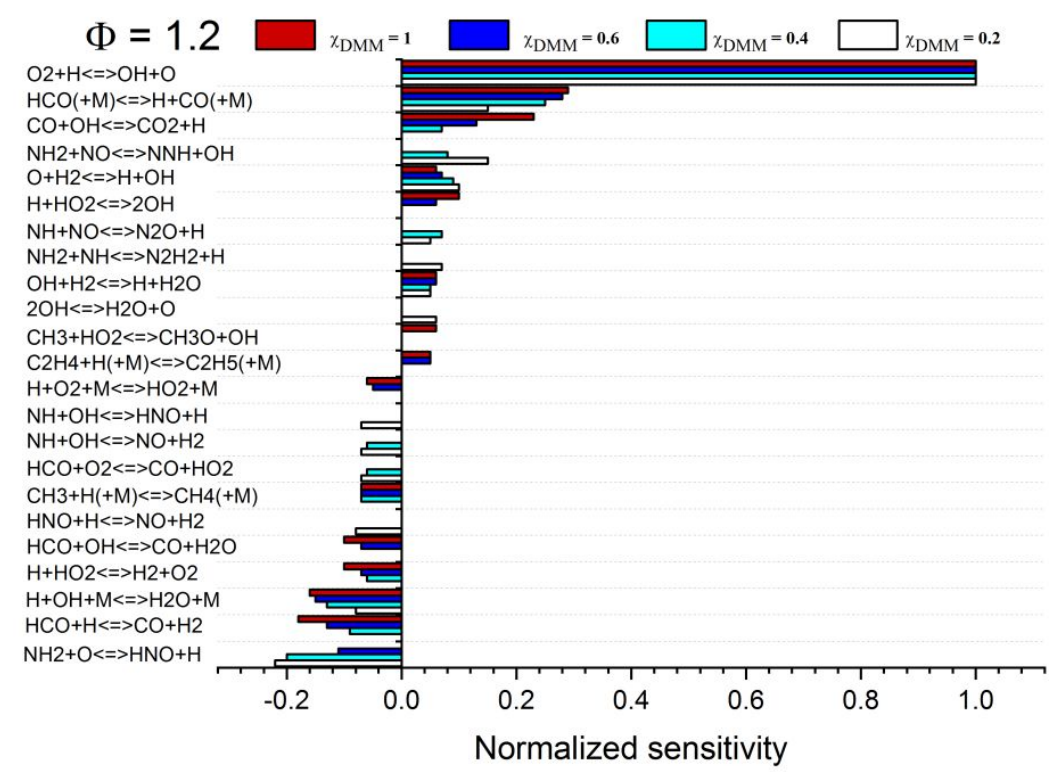

Figure. 14. First-order normalized sensitivity of unstretched laminar burning velocity of $\mathrm{NH}_{3} / \mathrm{DMM}$-air flames for various $\chi_{D M M}$ and $\Phi=1.2$.

$\mathrm{NO}_{x}$ emission during ammonia combustion is a major concern which needs a closer attention before $\mathrm{NH}_{3}$ can be realized as a potential future fuel for practical applications. Here, we briefly assess the impact of $\chi_{D M M}$ on $\mathrm{NO}$ emissions for $\mathrm{DMM} / \mathrm{NH}_{3}$ blends. Fig. 15 illustrates the predicted NO mole fraction for varying DMM mole fractions in a stoichiometric mixture. As seen, NO production increases intially approaching its peak at $\chi_{\mathrm{DMM}}=0.3$ before it starts decreasing for higher DMM content in the $\mathrm{NH}_{3} / \mathrm{DMM}$ blends. Neat DMM shows negligible NO emissions as expected. In ammonia flames, $\mathrm{NO}$ is generated via the oxidation pathways of $\mathrm{NH}_{i}(i=0,1,2)$ radicals, mainly through an $\mathrm{HNO}$ intermediate. $\mathrm{NH}_{i}$ radicals plays a critical role to reduce $\mathrm{NO}$ via $\mathrm{NH}_{i}+\mathrm{NO}$ reaction. The key combustion species for converting $\mathrm{NH}_{i}$ into $\mathrm{NO}$ are $\mathrm{O}, \mathrm{OH}, \mathrm{H}$ and $\mathrm{O}_{2}$. Under flame conditions, the increased concentration of these species favors the conversions of $\mathrm{NH}_{i}$ to $\mathrm{NO}$, and may inhibit the reduction of $\mathrm{NO}$ by $\mathrm{NH}_{i}$ radicals. Higher $\mathrm{NO}$ formation for the low mole fractions of DMM highlights the role of $\mathrm{NH}_{i}$ species, and also the prompt $\mathrm{NO}$ channel via $\mathrm{CH}$ route (see Fig. $\mathrm{S} 3$ for $\mathrm{NH}_{2}$ and $\mathrm{CH}$ radicals profiles for unstretched adiabatic neat $\mathrm{NH}_{3}$, 
$\mathrm{DMM}$, and $\mathrm{DMM} / \mathrm{NH}_{3}$-air flames at $\Phi=1$ ). The negligible NO formation in the neat DMM flames compared to the $\mathrm{DMM} / \mathrm{NH}_{3}$ blends indicates that the prompt $\mathrm{NO}$ contribution to the $\mathrm{NO}$ formation is minor compared to the fuel NO pathway. However, we note here that the results displayed in Fig. 15 strongly depends upon the adiabatic flame temperatures and the equivalence ratio. In rich ammonia flames, the combination reaction of NHi radicals dominate which eventually lead into the formation of $\mathrm{N}_{2}$. Consequently, $\mathrm{NO}$ production is low for $\mathrm{NH}_{3}$ rich flames. Therefore, one can conclude that the $\mathrm{NO}$ level is mainly governed by the levels of $\mathrm{O} / \mathrm{H}$ and $\mathrm{NH}_{i}$ radicals. Moreover, the oxidaion of $\mathrm{HCN}$ can also affect $\mathrm{NO}$ formation. $\mathrm{HCN}$ is found to decrease with increasing $\chi_{\text {DMM }}$ (See Fig. S4 in the supplementary material). This warrants further investigation to explore the cross-reactions between carbond and nitrogen family impacting the NO emissions for various $\mathrm{DMM} / \mathrm{NH}_{3}$ blends at different equivalence ratio. To conclude, the addition of $\mathrm{DMM}$ to $\mathrm{NH}_{3}$ does not necessarly decrease the NO emission in the flame as one would expect. However, the model suggests that $\mathrm{NO}$ would start to decrease after reaching a certain mole fraction of DMM which is an interesting observation. This warrants further verification through speciation measurments.

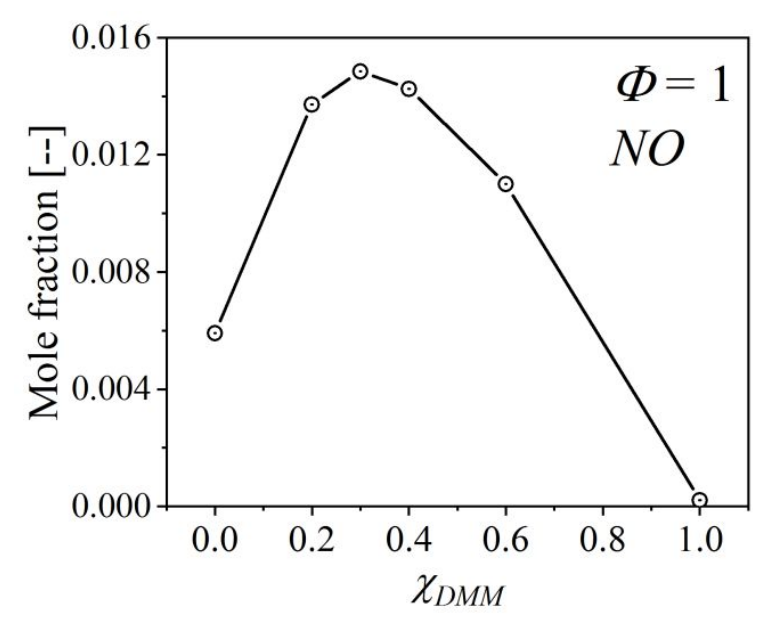

Figure 15. NO mole fraction at the post-flame zone as a function $\chi_{\mathrm{DMM}}$ at $\Phi=1, P_{i}=0.1 \mathrm{MPa}$, and $T_{i}=298 \mathrm{~K}$. 


\section{Conclusions}

Combustion characteristics $\mathrm{NH}_{3}$ blended with dimethoxymethane (DMM) were investigated using a constant volume chamber. This study finds that $\mathrm{DMM} / \mathrm{NH}_{3}$ blend can be a promising renewable fuel with enhanced combustion characteristics. In this work, the un-stretched adiabatic laminar burning velocity $\left(S_{L}\right)$ was measured for various $\mathrm{DMM} / \mathrm{NH}_{3}$ blends $\left(\chi_{\mathrm{DMM}}=0.2\right.$ to 0.6$)$ at $298 \mathrm{k}$ and $0.1 \mathrm{MPa}$, and $\Phi=0.8$ to 1.3 . In addition, numerical simulations using an assembled chemical kinetic model of $\mathrm{NH}_{3}$ and DMM sub-mechanisms were used to predict measured $S_{L}$. Some of the key findings are:

1. Addition of DMM was found to enhance the un-stretched laminar burning velocity significantly. For example, $S_{L}$ relative to neat $\mathrm{NH}_{3}$-air flames $\left(\mathrm{NH}_{3}\right.$-air flames data were taken from [28]) is enhanced by $\sim$ factor of 3 for the blend containing $\chi_{D M M}=0.2$ at $\Phi=1.1$, and by $\sim 125 \%$ compared to $\mathrm{CH}_{4} / \mathrm{NH}_{3}$ blend at $\chi_{\mathrm{DMM}}=\chi_{C H 4}=0.6, \Phi=1.1$. Interestingly, the highest enhancement of the flame speed with DMM was found at the richest and leanest limits.

2. The sensitivity of the flame to the stretch rate increases with a shift of $\Phi$ towards leaner mixtures and lower ammonia concentrations. This is indicated by a decrease in the burned gas Markestein length, $L_{b}$, with an increase in $\Phi$ (especially in the lean mixture blends).

3. Blending DMM with $\mathrm{NH}_{3}$ leads to an opposite evolution of $L_{b}$ with $\Phi$ relative to the observed $L_{b} / \Phi$ evolution in neat $\mathrm{NH}_{3}$ flames which showed negative values of $L_{b}$ at lean $\mathrm{NH}_{3}$-air flames.

4. The significant decrease in $L_{b}$ for the lean blend flames with $\Phi$ was driven mainly by the decline in lewis number $(L e)$, while both preheat flame thickness $\left(\delta_{L}\right)$, and Zeldovich-number 
(Ze) showed minor impacts. At the same $\Phi$ (lean mixtures), despite the notable decrease in both $\delta_{L}$ and $Z e$ with $\chi_{\mathrm{DMM}}, L_{b}$ was found to increase because of the significant rise of $L e$.

5. For DMM/NH $\mathrm{N}_{3}$ rich flames $\left(L e \approx 1\right.$, with no change with $\chi_{D M M}$ ), at high $\chi_{\mathrm{DMM}}=0.3-0.6, \delta_{L}$ shows a negligible variation with $\Phi$. However, for rich mixture at $\chi_{\mathrm{DMM}}=0.2, \delta_{L}$ is relatively high and increases with $\Phi$, leading to a slight increase of the flame sensitivity to the stretch rate. Moreover, the flame speed-stretch rate relationship shows different trajectories depending on Le number.

6. The proposed $\mathrm{NH}_{3} / \mathrm{DMM}$ chemical kinetic model performs excellently to predict $S_{L}$ for neat DMM flames and shows a reasonably good $S_{L}$ prediction for neat $\mathrm{NH}_{3}$ flames. Also, the model does reasonably well to capture the experimental data of $\mathrm{DMM} / \mathrm{NH}_{3}$ blends.

7. Reaction path analyses indicate that the oxidation of $\mathrm{NH}_{3} / \mathrm{DMM}$ blend can be treated as a parallel oxidation process of the individual fuels, which compete for the same radical pool $(\mathrm{OH}, \mathrm{H}, \mathrm{O})$ thus making the chemical system to be interwoven.

8. The dominant rate-limiting reactions in $\mathrm{DMM} / \mathrm{NH}_{3}$ flames, which govern the oxidation of $\mathrm{NH}_{3}$ are $\mathrm{NH}_{2}+\mathrm{NO}=\mathrm{NNH}+\mathrm{OH}$ and $\mathrm{NH}_{2}+\mathrm{O}=\mathrm{HNO}+\mathrm{H}$. These reactions have the most control over the radical pools for $\mathrm{NH}_{3}$ oxidation and thus impact significantly to $S_{L}$. The early arrival of CO radical in the flame compensates the shortage of the $\mathrm{O}$ and $\mathrm{OH}$ radicals for the rich flames, which enhances the flame laminar burning velocity.

\section{Acknowledgements}

The research reported in this publication was supported by the Office of Sponsored Research (OSR) at King Abdullah University of Science and Technology (KAUST). 


\section{Supporting information material}

The supporting information material file contains four supporting figures. In Fig. S1, the OH, H, $\mathrm{O}$, and $\mathrm{HO} 2$ radicals profiles for unstretched adiabatic DMM/NH3-air flames at $\Phi=1$ for varies $\mathrm{DMM} / \mathrm{NH} 3$ blends are presented. The variation of the adiabatic flame temperature of DMM/NH3air flames with $\Phi$ for the different DMM/NH3 blends are shown in Fig. S2. Figure S3 illustrates the $\mathrm{NH} 2$ and $\mathrm{CH}$ radicals profiles for unstretched adiabatic DMM/NH3-air flames for $\Phi=1$ premixed mixtures. Finally, the HCN radicals profiles for unstretched stoichiometric DMM/NH3air flames are presented for varies $\mathrm{DMM} / \mathrm{NH} 3$ blending ratios.

\section{References}

[1] Hayakawa A, Goto T, Mimoto R, Arakawa Y, Kudo T, Kobayashi H. Laminar burning velocity and Markstein length of ammonia/air premixed flames at various pressures. Fuel 2015;159:98-106.

[2] Okafor EC, Naito Y, Colson S, Ichikawa A, Kudo T, Hayakawa A, et al. Experimental and numerical study of the laminar burning velocity of $\mathrm{CH} 4-\mathrm{NH} 3-$ air premixed flames. Combustion and Flame 2018;187:185-98.

[3] Michalsky R, Parman BJ, Amanor-Boadu V, Pfromm PH. Solar thermochemical production of ammonia from water, air and sunlight: Thermodynamic and economic analyses. Energy 2012;42(1):251-60.

[4] Verkamp F, Hardin M, Williams J. Ammonia combustion properties and performance in gasturbine burners. Symp. (Int.) Combust. . 11. Elsevier; 1967:985-92.

[5] Kobayashi H, Hayakawa A, Somarathne KKA, Okafor EC. Science and technology of ammonia combustion. Proceedings of the Combustion Institute 2019;37(1):109-33.

[6] HENSHAW PF, D'ANDREA T, MANN KR, TING DS-K. Premixed ammonia-methane-air combustion. Combustion science and technology 2005;177(11):2151-70.

[7] Bockhorn H, Fetting F, Mende J. The laminar flame velocities of propane/ammonia mixtures. Combustion and Flame 1972;18(3):471-3.

[8] Lee J, Kim J, Park J, Kwon O. Studies on properties of laminar premixed hydrogen-added ammonia/air flames for hydrogen production. international journal of hydrogen energy 2010;35(3):1054-64.

[9] Otomo J, Koshi M, Mitsumori T, Iwasaki H, Yamada K. Chemical kinetic modeling of ammonia oxidation with improved reaction mechanism for ammonia/air and ammonia/hydrogen/air combustion. International Journal of Hydrogen Energy 2018;43(5):3004-14.

[10] Oestreich D, Lautenschütz L, Arnold U, Sauer J. Production of oxymethylene dimethyl ether (OME)-hydrocarbon fuel blends in a one-step synthesis/extraction procedure. Fuel 2018;214:3944.

[11] Burger J, Siegert M, Ströfer E, Hasse H. Poly (oxymethylene) dimethyl ethers as components of tailored diesel fuel: Properties, synthesis and purification concepts. Fuel 2010;89(11):3315-9.

[12] Song H, Liu C, Li F, Wang Z, He X, Shuai S, et al. A comparative study of using diesel and PODEn as pilot fuels for natural gas dual-fuel combustion. Fuel 2017;188:418-26. 
[13] Liu J, Sun P, Huang H, Meng J, Yao X. Experimental investigation on performance, combustion and emission characteristics of a common-rail diesel engine fueled with polyoxymethylene dimethyl ethers-diesel blends. Applied Energy 2017;202:527-36.

[14] Zhang X, Oyedun AO, Kumar A, Oestreich D, Arnold U, Sauer J. An optimized process design for oxymethylene ether production from woody-biomass-derived syngas. Biomass and Bioenergy 2016;90:7-14.

[15] Schmitz N, Burger J, Ströfer E, Hasse H. From methanol to the oxygenated diesel fuel poly (oxymethylene) dimethyl ether: An assessment of the production costs. Fuel 2016;185:67-72.

[16] Ryu K, Zacharakis-Jutz GE, Kong S-C. Performance characteristics of compression-ignition engine using high concentration of ammonia mixed with dimethyl ether. Applied energy 2014;113:48899.

[17] Gross CW, Kong S-C. Performance characteristics of a compression-ignition engine using directinjection ammonia-DME mixtures. Fuel 2013;103:1069-79.

[18] Härtl M, Seidenspinner P, Jacob E, Wachtmeister G. Oxygenate screening on a heavy-duty diesel engine and emission characteristics of highly oxygenated oxymethylene ether fuel OME1. Fuel 2015;153:328-35.

[19] Lautenschütz L, Oestreich D, Seidenspinner P, Arnold U, Dinjus E, Sauer J. Physico-chemical properties and fuel characteristics of oxymethylene dialkyl ethers. Fuel 2016;173:129-37.

[20] Song KH, Litzinger TA. Effects of dimethyoxymethane blending into diesel fuel on soot in an optically accessible DI diesel engine. Combustion science and technology 2006;178(12):2249-80.

[21] Westbrook CK, Pitz WJ, Curran HJ. Chemical kinetic modeling study of the effects of oxygenated hydrocarbons on soot emissions from diesel engines. The journal of physical chemistry A 2006;110(21):6912-22.

[22] Zhu R, Wang X, Miao H, Yang X, Huang Z. Effect of dimethoxy-methane and exhaust gas recirculation on combustion and emission characteristics of a direct injection diesel engine. Fuel 2011;90(5):1731-7.

[23] Huang Z, Ren Y, Jiang D, Liu L, Zeng K, Liu B, et al. Combustion and emission characteristics of a compression ignition engine fuelled with diesel-dimethoxy methane blends. energy conversion and management 2006;47(11-12):1402-15.

[24] Omari A, Heuser B, Pischinger S. Potential of oxymethylenether-diesel blends for ultra-low emission engines. Fuel 2017;209:232-7.

[25] Vertin KD, Ohi JM, Naegeli DW, Childress KH, Hagen GP, McCarthy Cl, et al. Methylal and methylaldiesel blended fuels for use in compression-ignition engines. SAE Technical Paper; 1999.

[26] Thenert K, Beydoun K, Wiesenthal J, Leitner W, Klankermayer J. Ruthenium-Catalyzed Synthesis of Dialkoxymethane Ethers Utilizing Carbon Dioxide and Molecular Hydrogen. Angewandte Chemie International Edition 2016;55(40):12266-9.

[27] Sun R, Delidovich I, Palkovits R. Dimethoxymethane as a cleaner synthetic fuel: synthetic methods, catalysts, and reaction mechanism. ACS Catalysis 2019;9(2):1298-318.

[28] Han X, Wang Z, Costa M, Sun Z, He Y, Cen K. Experimental and kinetic modeling study of laminar burning velocities of $\mathrm{NH} 3$ /air, $\mathrm{NH} 3 / \mathrm{H} 2$ /air, $\mathrm{NH} 3 / \mathrm{CO} /$ air and $\mathrm{NH} 3 / \mathrm{CH} 4 /$ air premixed flames. Combustion and Flame 2019;206:214-26.

[29] Smith GP, Golden DM, Frenklach M, Moriarty NW, Eiteneer B, Goldenberg M, et al. GRI-Mech 3.0, 1999. URL http://www me berkeley edu/gri_mech 2011.

[30] U. Mechanism, Chemical-Kinetic mechanisms for combution applications, mechnical and aerospace engineering (combustion research), University of California at San Diego, 2014, https://web.eng.ucsd.edu/mae/groups/combustion/mechanism.html. 
[31] Shrestha KP, Vin N, Herbinet O, Seidel L, Battin-Leclerc F, Zeuch T, et al. Insights into nitromethane combustion from detailed kinetic modeling-Pyrolysis experiments in jet-stirred and flow reactors. Fuel 2020;261:116349.

[32] Sun W, Wang G, Li S, Zhang R, Yang B, Yang J, et al. Speciation and the laminar burning velocities of poly (oxymethylene) dimethyl ether 3 (POMDME3) flames: An experimental and modeling study. Proceedings of the Combustion Institute 2017;36(1):1269-78.

[33] Chen Z. On the accuracy of laminar flame speeds measured from outwardly propagating spherical flames: Methane/air at normal temperature and pressure. Combustion and Flame 2015;162(6):2442-53.

[34] Burke MP, Chen Z, Ju Y, Dryer FL. Effect of cylindrical confinement on the determination of laminar flame speeds using outwardly propagating flames. Combustion and Flame 2009;156(4):771-9.

[35] Coleman HW, Steele Jr WG, Steele WG. Experimentation and uncertainty analysis for engineers. John Wiley \& Sons; 1999.

[36] Ronney PD, Wachman HY. Effect of gravity on laminar premixed gas combustion I: Flammability limits and burning velocities. Combustion and Flame 1985;62(2):107-19.

[37] Mannaa O, Mansour MS, Roberts WL, Chung SH. Laminar burning velocities at elevated pressures for gasoline and gasoline surrogates associated with RON. Combustion and Flame 2015;162(6):2311-21.

[38] Sarathy SM, Brequigny P, Katoch A, Elbaz AM, Roberts WL, Dibble RW, et al. Laminar Burning Velocities and Kinetic Modeling of a Renewable E-Fuel: Formic Acid and Its Mixtures with $\mathrm{H} 2$ and CO2. Energy \& Fuels 2020.

[39] Egolfopoulos FN, Hansen N, Ju Y, Kohse-Höinghaus K, Law CK, Qi F. Advances and challenges in laminar flame experiments and implications for combustion chemistry. Progress in Energy and Combustion Science 2014;43:36-67.

[40] Clavin P. Dynamic behavior of premixed flame fronts in laminar and turbulent flows. Progress in energy and combustion science 1985;11(1):1-59.

[41] Kelley AP, Law CK. Nonlinear effects in the extraction of laminar flame speeds from expanding spherical flames. Combustion and Flame 2009;156(9):1844-51.

[42] Law CK, Jomaas G, Bechtold JK. Cellular instabilities of expanding hydrogen/propane spherical flames at elevated pressures: theory and experiment. Proceedings of the Combustion Institute 2005;30(1):159-67.

[43] Dinkelacker F, Manickam B, Muppala S. Modelling and simulation of lean premixed turbulent methane/hydrogen/air flames with an effective Lewis number approach. Combustion and Flame 2011;158(9):1742-9.

[44] Muppala S, Nakahara M, Aluri N, Kido H, Wen J, Papalexandris M. Experimental and analytical investigation of the turbulent burning velocity of two-component fuel mixtures of hydrogen, methane and propane. international journal of hydrogen energy 2009;34(22):9258-65.

[45] Bouvet N, Halter F, Chauveau C, Yoon Y. On the effective Lewis number formulations for lean hydrogen/hydrocarbon/air mixtures. International journal of hydrogen energy 2013;38(14):594960.

[46] Okafor EC, Naito Y, Colson S, Ichikawa A, Kudo T, Hayakawa A, et al. Measurement and modelling of the laminar burning velocity of methane-ammonia-air flames at high pressures using a reduced reaction mechanism. Combustion and Flame 2019;204:162-75.

[47] Chen Z, Ju Y. Theoretical analysis of the evolution from ignition kernel to flame ball and planar flame. Combustion Theory and Modelling 2007;11(3):427-53.

[48] Wu F, Liang W, Chen Z, Ju Y, Law CK. Uncertainty in stretch extrapolation of laminar flame speed from expanding spherical flames. Proceedings of the Combustion Institute 2015;35(1):663-70. 
[49] Chen Z. On the extraction of laminar flame speed and Markstein length from outwardly propagating spherical flames. Combustion and Flame 2011;158(2):291-300.

[50] Bradley D, Gaskell PH, Gu X. Burning velocities, Markstein lengths, and flame quenching for spherical methane-air flames: a computational study. Combustion and flame 1996;104(1-2):17698.

[51] Müller U, Bollig M, Peters N. Approximations for burning velocities and Markstein numbers for lean hydrocarbon and methanol flames. Combustion and Flame 1997;108(3):349-56.

[52] Okafor EC, Nagano Y, Kitagawa T. Experimental and theoretical analysis of cellular instability in lean $\mathrm{H} 2$-CH4-air flames at elevated pressures. international journal of hydrogen energy 2016;41(15):6581-92.

[53] Bechtold J, Matalon M. The dependence of the Markstein length on stoichiometry. Combustion and flame 2001;127(1-2):1906-13.

[54] Peters N, Williams F. The asymptotic structure of stoichiometric methane? air flames. Combustion and flame 1987;68(2):185-207.

[55] Bradley D, Sheppart C, Woolley R, Greenhalgh D, Lockett R. The development and structure of flame instabilities and cellularity at low Markstein numbers in explosions. Combustion and flame 2000;122(1-2):195-209.

[56] Shrestha KP, Seidel L, Zeuch T, Mauss F. Detailed kinetic mechanism for the oxidation of ammonia including the formation and reduction of nitrogen oxides. Energy \& fuels 2018;32(10):10202-17.

[57] Gillespie FR. An experimental and modelling study of the combustion of oxygenated hydrocarbons. Ireland: NUIG Galway; 2014.

[58] Shrestha KP, Eckart S, Elbaz AM, Giri BR, Fritsche C, Seidel L, et al. A comprehensive kinetic model for dimethyl ether and dimethoxymethane oxidation and NOx interaction utilizing experimental laminar flame speed measurements at elevated pressure and temperature. Combustion and Flame 2020;218:57-74.

[59] Jabbour T, Clodic DF. Burning Velocity and Refrigerant Flammability Classification/DISCUSSION. ASHRAE Transactions 2004;110:522.

[60] Ronney PD. Effect of chemistry and transport properties on near-limit flames at microgravity. Combustion Science and Technology 1988;59(1-3):123-41.

[61] Takizawa K, Takahashi A, Tokuhashi K, Kondo S, Sekiya A. Burning velocity measurements of nitrogen-containing compounds. Journal of hazardous materials 2008;155(1-2):144-52.

[62] Pfahl U, Ross M, Shepherd J, Pasamehmetoglu K, Unal C. Flammability limits, ignition energy, and flame speeds in H2-CH4-NH3-N2O-O2-N2 mixtures. Combustion and Flame 2000;123(1-2):14058.

[63] Zakaznov V, Kursheva L, Fedina Z. Determination of normal flame velocity and critical diameter of flame extinction in ammonia-air mixture. Combustion, Explosion and Shock Waves 1978;14(6):710-3.

[64] Li Y, Bi M, Li B, Gao W. Explosion behaviors of ammonia-air mixtures. Combustion Science and Technology 2018;190(10):1804-16.

[65] Mei B, Zhang X, Ma S, Cui M, Guo H, Cao Z, et al. Experimental and kinetic modeling investigation on the laminar flame propagation of ammonia under oxygen enrichment and elevated pressure conditions. Combustion and Flame 2019;210:236-46.

[66] Kuo KK. Principles of combustion. 2005.

[67] Shrestha KP, Eckart S, Elbaz A M, Giri B R, Fritsche C, Seidel L, Roberts W L, Krause H, Mauss F. A comprehensive kinetic model for dimethyl ether and dimethoxymethane oxidation and NOx interaction utilizing experimental laminar flame speed measurements at elevated pressure and temperature. Combustion and Flame 2020; 218:57-74. 
[68] Hochgreb S, Dryer F. A comprehensive study on $\mathrm{CH} 2 \mathrm{O}$ oxidation kinetics. Combustion and flame 1992;91(3-4):257-84.

[69] Westbrook CK, Dryer FL. Chemical kinetic modeling of hydrocarbon combustion. Progress in Energy and Combustion Science 1984;10(1):1-57. 


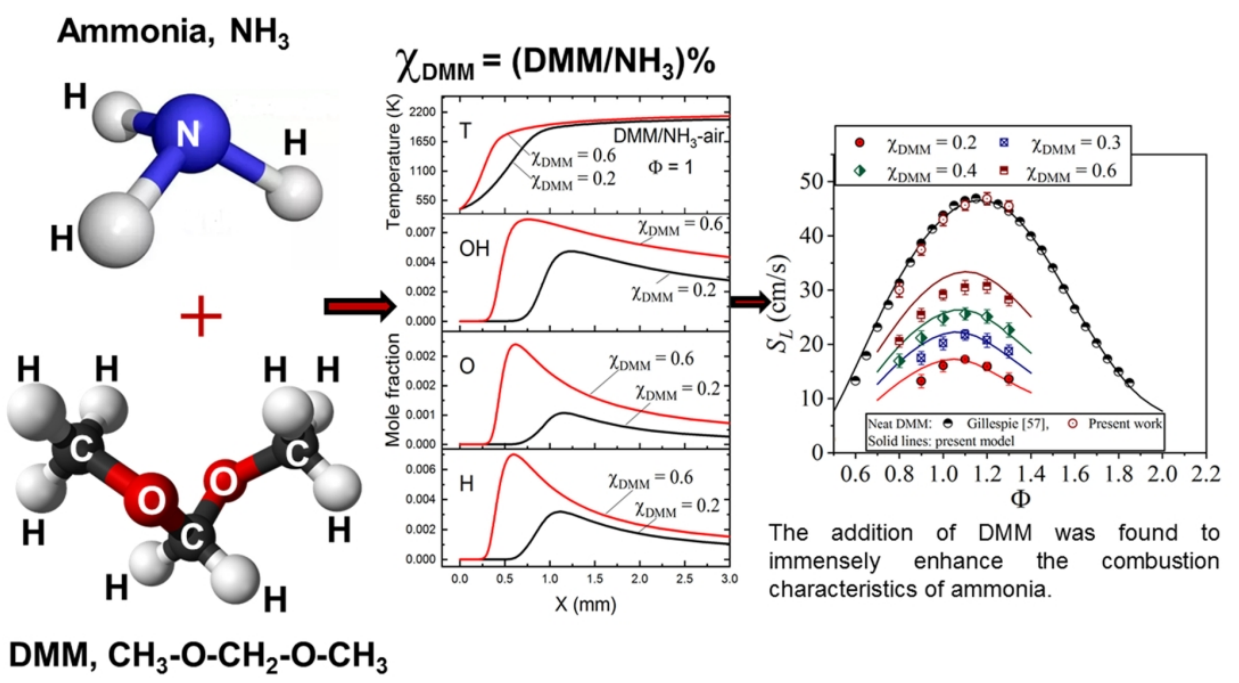

$82 \times 44 \mathrm{~mm}(600 \times 600$ DPI $)$ 